\title{
A SHAPE-FINDING ANALYSIS OF SUSPENDED STRUCTURES ON THE DISPLACEMENT-METHOD EQUILIBRIUM
}

\author{
Masahiro $\mathrm{AI}^{1}$ and Hironori IMAI ${ }^{2}$ \\ ${ }^{1}$ Mem. of JSCE, Dr.Eng., Professor, Dept. of Civil Eng., Hosei Univ. \\ (Koganei Tokyo 184-8584, Japan) \\ 2 M.Eng., Teacher, Dept. of Civil Eng., Iidaosahime High School \\ (Kanaenagokuma Iida Nagano 395-0804, Japan)
}

\begin{abstract}
By its geometrical nonlinearity, the realization of a desired suspension structure depends on the shape-finding procedure. In an actual suspension structure, cable members are usually combined with bending members. For a beam-cable structure, in this study, the displacement method is employed to deal with the structural equilibrium, but in which each cable member is treated as the elastic catenary through a force-method computation. Thereafter an iterative scheme of shape finding is developed for such a mixture of cable and beam members, which is based on the tangent coefficients to change of the cable natural lengths on each updated equilibrium configuration.
\end{abstract}

Key Words : shape finding, displacement method, elastic catenary, iteration

\section{INTRODUCTION}

The suspension bridge has a long history since before the computational age. In the cable-stayed bridge, from its earlier stage, the statically indeterminate forces have been estimated with the aid of computers. In the recent discrete methods, the static behaviors of such a beam-cable structure can be known with a sufficient accuracy. On the other hand, beyond those established ones, there could be other suspension forms remaining to be developed according to circumstances.

In principle, the configuration of a cable structure is known as a result of equilibrium analysis. So a general suspension structure necessitates the "shape-finding" procedure in its erection: to fulfill the design requirements, the equilibrium state needs to be settled in variation of structural parameters such as the cable lengths. There have been various approaches to that problem. ${ }^{1)-9)}$ The force density method in Ref. 4) is based on one notable feature of a general network: once the force densities (tension/length ratios) are assumed in members, the discrete equilibrium equations become linear for the joint coordinates. Through the linear solution, those force densities have a direct correspondence to the equilibrium shape, and so could be favorable parameters in the shape finding. In Ref.6), after the same parameters are employed, an arbitrary number of requirements such as more than the variable parameters are dealt with upon a suggested objective function through the optimization procedure. Those existing methods are developed for an assembly of straight cable and axial members. But, in a usual suspended structure, the cables are combined with column and beam members.

Practically, a pretensioned cable is represented by the simple tension member. But, a long selfweighted cable such as in a large-scale structure needs to be divided into several segments. For the accuracy, the sag-embodied elements are available: a shallow cable is described in the parabolic profile e.g. 10); and the catenary theory can deal with a deeply hanging cable in one segment. e.g. 11),12) In either of them, the expression for tension components is implicit in terms of its span coordinates. This compatibility condition in each element has to be treated numerically, prior to the structural computations.

Because of its capability to various discrete models, the displacement method is employed for the present equilibrium computation of a beamcable structure, in which both the simple tension element and the elastic catenary element are prepared for each cable member. This study is to de- 

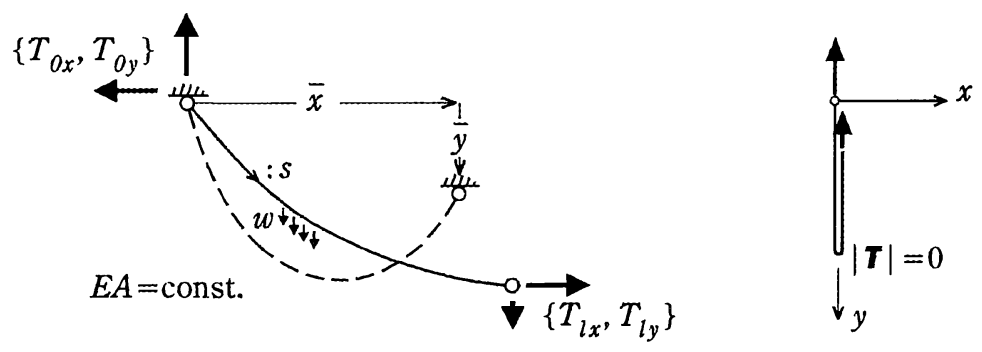

$$
T_{l \dot{x}}=0 \text { and }-w l \leq T_{l y} \leq 0
$$

Fig. 1 Catenary cable

velop a shape finding scheme for such a mixture of cable and beam members, based on the tangent coefficients of equilibrium quantities to the variable natural lengths of cable and axial members. The shape settlement is executed in combination with the equilibrium computation: the responsive equilibrium state is determined after each correction of member lengths; and the next correction is estimated tangentially upon that updated configuration. The two structural iterations are layered. In each of them, the fractional correction technique ${ }^{7), 8)}$ is adopted so that inthe-midst states are not thrown far away from an expected correction path.

\section{ELASTIC CATENARY ELEMENT}

In the 2-D space, consider a uniform flexible cable of natural length $l$, extension rigidity $E A$ and weight $w$ per unit length. Firstly, as shown in Fig. 1, let this cable be anchored at one end to the origin of rectangular coordinates $\{x, y\}$. After material coordinate $s$ is taken along its natural length, the configuration is here described in the form $\{x(s), y(s)\}$.

When tensioned by $\left\{T_{0 x}, T_{0 y}\right\}$ at $s=0$, the internal components under $w$ into $y$-direction are $\left\{T_{x}(s), T_{y}(s)\right\}=\left\{T_{0 x}, T_{0 y}-w s\right\}$. Submitted to $T(s)=\sqrt{T_{x}(s)^{2}+T_{y}(s)^{2}}$, differential element $d s$ is elongated to $d \bar{s}=(1+T(s) /(E A)) d s$; and, by the flexibility, this $d \bar{s}$ is laid in the same direction to $\left\{T_{x}(s), T_{y}(s)\right\}$. By those two, the spatial components of $d s$ is eventually written in terms of $\left\{T_{x}(s), T_{y}(s)\right\}$ :

$$
\left\{\begin{array}{l}
d x \\
d y
\end{array}\right\}=\left(\frac{1}{T(s)}+\frac{1}{E A}\right)\left\{\begin{array}{l}
T_{x}(s) \\
T_{y}(s)
\end{array}\right\} d s
$$

By the actual integration, we have

$$
x\left(\boldsymbol{T}_{0} ; s\right)=\frac{T_{0 x} s}{E A}
$$

$$
\begin{aligned}
& +\frac{T_{0 x}}{w} \log \left\{\frac{\sqrt{T_{0 x}^{2}+T_{0 y}^{2}}+T_{0 y}}{\sqrt{T_{0 x}^{2}+\left(T_{0 y}-w s\right)^{2}}+\left(T_{0 y}-w s\right)}\right\} \\
& y\left(\boldsymbol{T}_{0} ; s\right)=\frac{T_{0 y} s-\frac{w}{2} s^{2}}{E A} \\
& +\frac{1}{w}\left\{\sqrt{T_{0 x}^{2}+T_{0 y}^{2}}-\sqrt{T_{0 x}^{2}+\left(T_{0 y}-w s\right)^{2}}\right\}
\end{aligned}
$$

in which $\left\{T_{0 x}, T_{0 y}\right\}$ act as parameters in the spatial curve. This expression is the so-called "elastic catenary," which has been presented by Rough. 13)

Through relation $\left\{T_{l x}, T_{l y}\right\}=\left\{T_{0 x}, T_{0 y}-\right.$ $w l\}$, either $\boldsymbol{T}_{\mathbf{0}}$ or $\boldsymbol{T}_{l}$ can be taken as the independent parameters. By differentiating the above (2) with respect to $\boldsymbol{T}_{l}\left(\delta \boldsymbol{T}_{l}=\delta \boldsymbol{T}_{\mathbf{0}}=\delta \boldsymbol{T}(s)\right)$, we have the tangent flexibility matrix between $\boldsymbol{x}_{l}=$ $\boldsymbol{x}\left(\boldsymbol{T}_{l} ; l\right)$ and $\boldsymbol{T}_{l}$ :

$$
\begin{aligned}
& \left\{\begin{array}{l}
\delta x_{l} \\
\delta y_{l}
\end{array}\right\}=\left[Q\left(\boldsymbol{T}_{l}\right)\right]\left\{\begin{array}{c}
\delta T_{l x} \\
\delta T_{l y}
\end{array}\right\} \\
& Q_{x x}=\frac{l}{E A} \\
& \quad+\frac{1}{w}\left\{\log \left(\frac{T_{0}+T_{0 y}}{T_{l}+T_{l y}}\right)+\frac{T_{l y}}{T_{l}}-\frac{T_{0 y}}{T_{0}}\right\} \\
& Q_{x y}=Q_{y x}=\frac{T_{0 x}}{w}\left(\frac{1}{T_{0}}-\frac{1}{T_{l}}\right) \\
& Q_{y y}=\frac{l}{E A}+\frac{1}{w}\left(\frac{T_{0 y}}{T_{0}}-\frac{T_{l y}}{T_{l}}\right)
\end{aligned}
$$

where $T_{0}=\sqrt{T_{0 x}^{2}+T_{0 y}^{2}}$ and $T_{l}=\sqrt{T_{l x}^{2}+T_{l y}^{2}}$. So far as $\left\{T_{x}(s), T_{y}(s)\right\} \neq\{0,0\}$ in $0 \leq s \leq l$, matrix $\left[Q\left(\boldsymbol{T}_{l}\right)\right]$ is kept positive definite. ${ }^{7)}$ If $T_{l x}=0$ and $-w l \leq T_{l y} \leq 0$ (a line segment in $\left\{T_{l x}, T_{l y}\right\}$ space), the cable has a point of $\left\{T_{x}(a), T_{y}(a)\right\}=$ $\{0,0\}$, and is bent back in a vertical hanging (see Fig. 1). In this configuration, derivative matrix $\left[Q\left(\boldsymbol{T}_{l}\right)\right]$ becomes singular into the direction 
normal to the line segment, $\partial x_{l} / \partial T_{l x} \rightarrow \infty$. But, function $\boldsymbol{x}_{l}\left(\boldsymbol{T}_{l}\right)$ itself is continuous over the entire domain. By the symmetry of $\left[Q\left(\boldsymbol{T}_{l}\right)\right]$, differential $\delta F=x_{l}\left(\boldsymbol{T}_{l}\right) \delta T_{l x}+y_{l}\left(\boldsymbol{T}_{l}\right) \delta T_{l y}$ is pathindependently integrable, and, by its positive definiteness, the resulting potential $F\left(\boldsymbol{T}_{l}\right)$ is properly convex :

$$
\begin{aligned}
& F\left(\boldsymbol{T}_{l}\right)=\frac{1}{2 w}\left\{T_{0 x}^{2} \log \left(\frac{T_{0}+T_{0 y}}{T_{l}+T_{l y}}\right)+T_{0 y} T_{0}\right. \\
& \left.-T_{l y} T_{l}\right\}+\frac{l}{2 E A}\left\{T_{0 x}^{2}+\frac{1}{3 w l}\left(T_{0 y}^{3}-T_{l y}^{3}\right)\right\}
\end{aligned}
$$

Consider joint $i$ and $j$ to which cable element (c) is attached, with their spatial positions being denoted by $\boldsymbol{x}_{i}$ and $\boldsymbol{x}_{j}$. In the displacementmethod computation, those joint positions are iteratively approximated toward the structural equilibrium. On such momentary joint positions, all the catenary elements have to be computed for $\left\{T_{l x}, T_{l y}\right\}_{(c)}$ corresponding to their span coordinates, $\overline{\boldsymbol{x}}=\boldsymbol{x}_{\boldsymbol{j}}-\boldsymbol{x}_{i}$. In this compatibility problem of each element $(c)$, a total complementary potential is defined by $W^{*}\left(\boldsymbol{T}_{l}\right)=F\left(\boldsymbol{T}_{l}\right)-\overline{\boldsymbol{x}}^{T} \boldsymbol{T}_{l}$, and the unique solution can be found numerically as a point to minimize $W^{*}\left(\boldsymbol{T}_{l}\right) .{ }^{12)}$

After the above force-method computation, the tension components to span $\overline{\boldsymbol{x}}$ are rewritten as a displacement-method element into

$$
\begin{aligned}
\{\boldsymbol{T}\}_{(c)} & \left(=\left\{\boldsymbol{T}_{\boldsymbol{i}}, \boldsymbol{T}_{j}\right\}\right) \\
& =\left\{\left(-T_{0 x},-T_{0 y}\right),\left(T_{l x}, T_{l y}\right)\right\}
\end{aligned}
$$

Matrix $\left[Q\left(\boldsymbol{T}_{l}\right)\right]$ is inverted into tangent stiffness $\left[\bar{k}\left(\boldsymbol{T}_{l}\right)\right]_{(c)}$, and which is rewritten into the full $4 \times 4$ matrix $\left[k\left(\boldsymbol{T}_{l}\right)\right]_{(c)}$ between $\left\{\delta \boldsymbol{T}_{i}, \delta \boldsymbol{T}_{j}\right\}$ and $\left\{\delta \boldsymbol{x}_{i}, \delta \boldsymbol{x}_{j}\right\}$. According to Ref. 14), the strain energy $U_{(c)}$ and the self-weight potential $V_{(c)}$ are obtained as follows :

$$
\begin{gathered}
U_{(c)}\left(\boldsymbol{T}_{l}\right)\left(=\int_{0}^{l} \frac{T^{2}}{2 E A} d s\right) \\
=\frac{1}{2 E A}\left\{T_{0 x}^{2} l+\frac{1}{3 w}\left(T_{0 y}^{3}-T_{l y}^{3}\right)\right\}(7 \\
V_{(c)}\left(\boldsymbol{T}_{l}, y_{i}\right)\left(=-\int_{0}^{l} w y(s) d s\right) \\
=-w l y_{i}-T_{0} l-\frac{1}{2 w}\left(T_{l} T_{l y}-T_{0} T_{0 y}\right) \\
+\frac{T_{0 x}^{2}}{2 w} \log \left(\frac{T_{0}+T_{0 y}}{T_{l}+T_{l y}}\right) \\
-\frac{w}{E A}\left(\frac{T_{0 y} l^{2}}{2}-\frac{w l^{3}}{6}\right)
\end{gathered}
$$

The work done by $\left\{\boldsymbol{T}_{i}, \boldsymbol{T}_{j}\right\}$ during change of $\left\{\boldsymbol{x}_{i}, \boldsymbol{x}_{j}\right\}$ is stored into those $U_{(c)}\left(\boldsymbol{T}_{l}\right)$ and

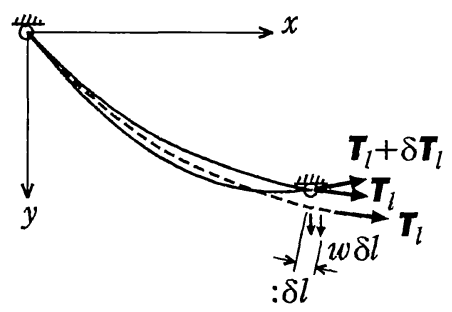

Fig. 2 Isolated cable for increment $\delta l$

$V_{(c)}\left(\boldsymbol{T}_{l}, y_{i}\right)$. When joint $i$ is fixed in the space (see Fig. 1), by the positive definiteness of $\left[\bar{k}\left(\boldsymbol{T}_{l}\right)\right]_{(c)}$ (kept from $\left.\left[Q\left(\boldsymbol{T}_{l}\right)\right]\right)$, the sum $U_{(c)}\left(\boldsymbol{T}_{l}\right)+V_{(c)}\left(\boldsymbol{T}_{l}\right)$ is convex with respect to $\boldsymbol{T}_{l}$.

In Sec. 5, the equilibrium response to variation of the cable lengths will be argued to develop a shape-finding procedure. With regard to this structural response, an essential behavior is seen in an isolated cable. As shown in Fig. 2, let an infinitesimal increment $\delta l$ of natural length be assumed in the catenary equilibrium, with span coordinates $\{\bar{x}, \bar{y}\}$ being fixed. If the tension components are unchanged, the cable is simply lengthened at its fore end: according to Eq.(1)

$$
\left\{\begin{array}{l}
\delta x_{l} \\
\delta y_{l}
\end{array}\right\}=\left(\frac{1}{\left|\boldsymbol{T}_{l}\right|}+\frac{1}{E A}\right)\left\{\begin{array}{l}
T_{l x} \\
T_{l y}
\end{array}\right\} \delta l
$$

In the cable spanned to $\{\bar{x}, \bar{y}\}$, those $\left\{\delta x_{l}, \delta y_{l}\right\}$ are offset by a simultaneous change of $\boldsymbol{T}(s)$. In addition to $\left\{\delta T_{l x}, \delta T_{l y}\right\}$, the self weight is increased by $w \delta l$ :

$$
\left\{\begin{array}{l}
\delta T_{x}(s) \\
\delta T_{y}(s)
\end{array}\right\}=\left\{\begin{array}{l}
\delta T_{l x} \\
\delta T_{l y}
\end{array}\right\}+\left\{\begin{array}{c}
0 \\
w
\end{array}\right\} \delta l \text { : const. }
$$

Applying this $\left\{\delta T_{x}(s), \delta T_{y}(s)\right\}$ to the flexibility matrix, we have the compatibility equations

$$
\begin{aligned}
& {\left[Q\left(\boldsymbol{T}_{l}\right)\right]\left(\left\{\begin{array}{c}
\delta T_{l \boldsymbol{x}} \\
\delta T_{l y}
\end{array}\right\}+\left\{\begin{array}{c}
0 \\
w
\end{array}\right\} \delta l\right)} \\
& +\left(\frac{1}{\left|\boldsymbol{T}_{l}\right|}+\frac{1}{E A}\right)\left\{\begin{array}{l}
T_{l \boldsymbol{x}} \\
T_{l y}
\end{array}\right\} \delta l=\left\{\begin{array}{l}
0 \\
0
\end{array}\right\}
\end{aligned}
$$

The responsive $\{\delta \boldsymbol{T}\}_{(c)}$ is eventually written as follows :

$$
\begin{array}{r}
\delta\{\boldsymbol{T}\}_{(c)}=\{\boldsymbol{\psi}\}_{(c)} \delta l_{(c)}=\left\{\begin{array}{c}
-\boldsymbol{\psi}_{0} \\
\boldsymbol{\psi}_{l}
\end{array}\right\} \delta l_{(c)} \\
\boldsymbol{\psi}_{0}=-\left(\frac{1}{\left|\boldsymbol{T}_{l}\right|}+\frac{1}{E A}\right)\left[Q\left(\boldsymbol{T}_{l}\right)\right]^{-1} \\
\cdot\left\{\begin{array}{c}
T_{l x} \\
T_{l y}
\end{array}\right\} \\
\boldsymbol{\psi}_{l}=-\left(\frac{1}{\left|\boldsymbol{T}_{l}\right|}+\frac{1}{E A}\right)\left[Q\left(\boldsymbol{T}_{l}\right)\right]^{-1} \\
\cdot\left\{\begin{array}{c}
T_{l x} \\
T_{l y}
\end{array}\right\}-\left\{\begin{array}{c}
0 \\
w
\end{array}\right\}
\end{array}
$$




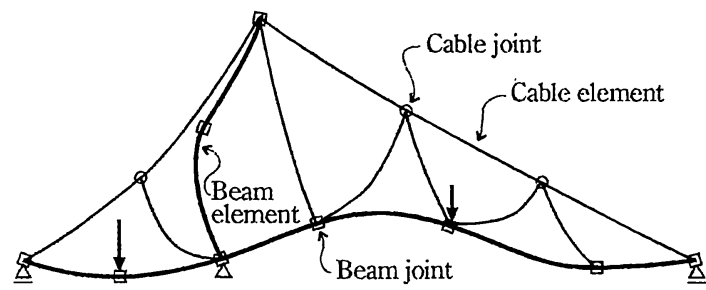

Fig. 3 Beam-cable structure

\section{CONTINUITY RELATIONS IN STRUCTURAL STIFFNESS}

Consider a two-dimensional assembly of cable and beam members, as shown in Fig. 3. The freedom of a beam joint is represented by its translational and angular coordinates in the space, $\boldsymbol{X}_{n}=$ $\{x, y, \theta\}_{n}$, with the force components being denoted by $\boldsymbol{F}_{n}=\left\{F_{x}, F_{y}, M\right\}_{n}$. At an intersection of two or more cables, a joint of another class is placed, which has joint position $\boldsymbol{x}_{i}=\{x, y\}_{i}$ and joint force $\boldsymbol{F}_{i}=\left\{F_{x}, F_{y}\right\}_{i}$. Those joint positions are collected into one column vector, $\left\{\boldsymbol{X}_{J}\right\}=$ $\left\{\boldsymbol{X}_{1}, \cdots, \boldsymbol{X}_{N}, \boldsymbol{x}_{1}, \cdots, \boldsymbol{x}_{I}\right\}(J=N+I)$. Excepting the constrained ones at the supports, we have the variable components of $\left\{\boldsymbol{X}_{J}\right\}$ listed into another $\left\{d_{\Gamma}\right\}=\left\{d_{1}, d_{2}, \cdots, d_{\Gamma}\right\}$. The corresponding joint forces are denoted by $\left\{\boldsymbol{F}_{J}\right\}$ and $\left\{F_{\Gamma}\right\}$, respectively.

The spatial configuration of each element is defined by its two joint positions: $\{\boldsymbol{X}\}_{[e]}=$ $\left\{\boldsymbol{X}_{m}, \boldsymbol{X}_{n}\right\}$ for a beam element, and $\{\boldsymbol{x}\}_{(c)}=$ $\left\{\boldsymbol{x}_{i}, \boldsymbol{x}_{j}\right\}$ for a cable element. The force components into $\{\boldsymbol{X}\}_{[e]}$ and $\{\boldsymbol{x}\}_{(c)}$ are denoted by $\{\boldsymbol{F}\}_{[e]}$ and $\{\boldsymbol{T}\}_{(c)}$, respectively. Those element positions are collected into their respective sets: $\left\{\boldsymbol{X}_{[E]}\right\}=\left\{\{\boldsymbol{X}\}_{[1]}, \cdots,\{\boldsymbol{X}\}_{[E]}\right\}$ and $\left\{\boldsymbol{x}_{(C)}\right\}=$ $\left\{\{\boldsymbol{x}\}_{(1)}, \cdots,\{\boldsymbol{x}\}_{(C)}\right\}$. Similarly, $\left\{\boldsymbol{F}_{[E]}\right\}$ and $\left\{\boldsymbol{T}_{(C)}\right\}$ stand for the element forces. Column vector $\left\{\boldsymbol{X}_{[E]}\right\}$ and $\left\{\boldsymbol{x}_{(C)}\right\}$ are related to $\left\{\boldsymbol{X}_{J}\right\}$ in the form ${ }^{\dagger}$

$$
\left\{\boldsymbol{X}_{[E]}\right\}=\left[S_{X}\right]\left\{\boldsymbol{X}_{J}\right\}, \quad\left\{\boldsymbol{x}_{(C)}\right\}=\left[S_{X}^{\prime}\right]\left\{\boldsymbol{X}_{J}\right\}
$$

where $\left[S_{X}\right]$ and $\left[S_{X}^{\prime}\right]$ are the continuity matrices, consisting of 0 and 1 .

As for the 2-D beam element, there have been presented certain nonlinear discretizations. The stiffness relations developed in the method of separation into rigid displacement and deformation ${ }^{15)}$ are employed in our elastic

\footnotetext{
${ }^{\dagger} \mathrm{A}$ beam element is attached to its two joints with certain fixed angles. In case the tangent angles at the both ends of its axial line are employed in $\{X\}_{[e]}$ rather than the joints' angular coordinates, no changes in other relations but $\left\{\boldsymbol{X}_{[E]}\right\}=\left[S_{X}\right]\left\{\boldsymbol{X}_{J}\right\}+\{$ const. $\}$.
}

finite-displacement analysis: the element force $\{\boldsymbol{F}\}_{[e]}\left(=\left\{\boldsymbol{F}_{m}, \boldsymbol{F}_{n}\right\}\right)$, the tangent stiffness matrix $[K]_{[e]}$ and the strain energy $U_{[e]}$ are evaluated for an assumed $\{\boldsymbol{X}\}_{[e]}$. In each cable element, positioned at $\{\boldsymbol{x}\}_{(c)}$, the cable tension $\{\boldsymbol{T}\}_{(c)}\left(=\left\{\boldsymbol{T}_{i}, \boldsymbol{T}_{j}\right\}\right)$, the tangent stiffness $[k]_{(c)}$, the strain energy $U_{(c)}$ and the self-weight potential $V_{(c)}$ are obtained through the force-method computation, Sec. 2.

In the structure, those element forces are accumulated into the joint forces, namely

$$
\left\{\boldsymbol{F}_{J}\right\}=\left[S_{F}\right]\left\{\boldsymbol{F}_{[E]}\right\}+\left[S_{F}^{\prime}\right]\left\{\boldsymbol{T}_{(C)}\right\}
$$

Those $\left[S_{F}\right]$ and $\left[S_{F}^{\prime}\right]$ are determined by the element-to-joint continuity, and so are not independent of the former $\left[S_{X}\right]$ and $\left[S_{X}^{\prime}\right]$ : by the contragredience

$$
\left[S_{F}\right]=\left[S_{X}\right]^{T} \text { and }\left[S_{F}^{\prime}\right]=\left[S_{X}^{\prime}\right]^{T}
$$

Let the external forces into the $\left\{d_{\Gamma}\right\}$-directions be denoted by $\left\{\bar{P}_{\Gamma}\right\}$. By extracting the corresponding components out of $\left\{\boldsymbol{F}_{J}\right\}$, we have the equilibrium equations for $\left\{d_{\Gamma}\right\}$ :

$$
\left(\left\{F_{\Gamma}\right\}=\right)\left[C^{F}\right]\left\{\boldsymbol{F}_{J}\right\}=\left\{\bar{P}_{\Gamma}\right\}
$$

where $\left[C^{F}\right]$ is a matrix of $\Gamma \times(3 N+2 I)$, consisting of 0 and 1 .

We next consider the tangent stiffness for differential $\delta\left\{d_{\Gamma}\right\}$. The variation of $\left\{\boldsymbol{X}_{J}\right\}$ is written as $\delta\left\{\boldsymbol{X}_{J}\right\}=\left[C^{F}\right]^{T} \delta\left\{d_{\Gamma}\right\}$. The differential relations of the former (13), (14) and (16) are apparent. Let the element tangent stiffness matrices be collected into $\delta\left\{\boldsymbol{F}_{[E]}\right\}=$ $\left[K_{[E]}\right] \delta\left\{\boldsymbol{X}_{[E]}\right\}$ and $\delta\left\{\boldsymbol{F}_{(C)}\right\}=\left[k_{(C)}\right] \delta\left\{\boldsymbol{x}_{(C)}\right\}$, where

$$
\begin{aligned}
{\left[K_{[E]}\right] } & =\left[\begin{array}{lll}
{[K]_{[1]}} & & \\
& \ddots & \\
& & {[K]_{[E]}}
\end{array}\right] \\
{\left[k_{(C)}\right] } & =\left[\begin{array}{lll}
{[k]_{(1)}} & & \\
& \ddots & \\
& & {[k]_{(C)}}
\end{array}\right]
\end{aligned}
$$

Then, by the chain rule, the tangent stiffness matrix on freedom $\left\{d_{\Gamma}\right\}$ is written as follows :

$$
\begin{aligned}
\delta\left\{F_{\Gamma}\right\} & =\left[K_{\Gamma}\left(\left\{d_{\Gamma}\right\}\right)\right] \delta\left\{d_{\Gamma}\right\} \\
{\left[K_{\Gamma}\right] } & =\left[C_{F}\right]\left[S_{F}\right]\left[K_{[E]}\right]\left[S_{X}\right]\left[C_{F}\right]^{T} \\
& +\left[C_{F}\right]\left[S_{F}^{\prime}\right]\left[k_{(C)}\right]\left[S_{X}^{\prime}\right]\left[C_{F}\right]^{T}
\end{aligned}
$$

The total potential energy is given by the sum of the elements' strain energies, the self-weight 
potentials in cables, and the potentials of external joint forces :

$$
\begin{array}{r}
W\left(\left\{d_{\Gamma}\right\}\right)=\sum_{[e]} U_{[e]}+\sum_{(c)}\left(U_{(c)}+V_{(c)}\right) \\
-\left\{\bar{P}_{\Gamma}\right\}^{T}\left\{d_{\Gamma}\right\}
\end{array}
$$

\section{ITERATION FOR EQUILIBRIUM}

The characteristics of cable members are, of course, reflected onto the equilibrium behavior of their suspended structure. First, let a mere assembly of the simple tension members be summarized. The stiffness relations as a discrete element are given in Appendix-A, together with the compressive axial member. Since each tension member has a clear domain of singularity, $\bar{l}$ (= $\left.\sqrt{\bar{x}^{2}+\bar{y}^{2}}\right) \leq l$, the assembly also has certain singular domains of $\left\{d_{\Gamma}\right\}$, in general. But, in the displacement method, such singular elements do not necessarily mean the structural singularity: so far as every free joint is chained through tensioned members to one or more supporting joints (anchored), irrespective of other slackened members, the tangent stiffness matrix between $\left\{F_{\Gamma}\right\}$ and $\left\{d_{\Gamma}\right\}$ is kept positive definite. ${ }^{8)}$ Only if some free joints are left not anchored, the structural tangent stiffness becomes singular. It is under those circumstances that the assembly has a semi-convex total potential with respect to $\left\{d_{\Gamma}\right\}$. The above sayings are true of the catenary cables also. However, as stated on its flexibility in Sec. 2, the singularity exhibited by a catenary element is much weak: only into the normal direction on a line segment of $\{\bar{x}, \bar{y}\}$, namely $\partial T_{l x} / \partial \bar{x} \rightarrow 0$ for $\bar{x}=0$ and $-l(1+w l / 2 E A) \leq$ $\bar{y} \leq l(1+w l / 2 E A)$. In such a case, its potential $U_{(c)}+V_{(c)}$ still remains properly convex with respect to $\{\bar{x}, \bar{y}\}$, and so is the total potential of their assembly, with respect to $\left\{d_{\Gamma}\right\}$.

In our structure consisting of beam and cable members, on the other hand, the total potential energy is not convex at an arbitrary $\left\{d_{\Gamma}\right\}$ : the structure could become unstable beyond its bucklings. The stability analysis on certain loading paths is essential to estimate the load-carrying capacity. But, in a shape-finding analysis, the principal loads are kept unchanged except for the cables' self-weights. The equilibrium configuration is settled through successive changes of the cable lengths. After each change of those lengths, the displacement-method computation is executed to determine the corresponding equilibrium state. Usually, desired in the shape finding is a stable equilibrium configuration. If equilibria in the midst of the settlement are allowed to go across the stability boundaries, the handling must become much complicated. The execution of our shape finding is confined to the extent where the tangent stiffness $\left[K_{\Gamma}\left(\left\{d_{\Gamma}\right\}\right)\right]$ is kept positive definite.

Suppose the cable lengths are changed upon a known equilibrium $\left\{d_{\Gamma}\right\}^{\prime}$. The equilibrium is shifted to another position, say $\left\{d_{\Gamma}\right\}^{\mathrm{E}}$. From the unbalanced joint forces, $\left\{F_{\Gamma}\right\}^{\prime}\left(\neq\left\{\bar{P}_{\Gamma}\right\}\right)$, estimated at $\left\{d_{\Gamma}\right\}^{\prime}$, the equilibrium computation is started to find $\left\{d_{\Gamma}\right\}^{\mathrm{E}}$. With those renewed cable lengths, it has been postulated that our structure has $\left\{d_{\Gamma}\right\}^{\prime}$ and $\left\{d_{\Gamma}\right\}^{\mathrm{E}}$ in one stable subdomain. The Newton-Raphson method seems suitable to such a local one-to-one between $\left\{F_{\Gamma}\right\}$ and $\left\{d_{\Gamma}\right\}$. Indeed, provided they are located close together, $\left\{d_{\Gamma}\right\}^{\mathrm{E}}$ is attained without fail. But, when $\left\{d_{\Gamma}\right\}^{\prime}$ has an actual distance to $\left\{d_{\Gamma}\right\}^{\mathrm{E}}$, the approximated $\left\{d_{\Gamma}\right\}$ 's in that method can be thrown away beyond the one-to-one boundary.

For a consistent convergence to $\left\{d_{\Gamma}\right\}^{\mathrm{E}}$, we here employ the fractional correction method. ${ }^{7), 12)}$ Consider the $\langle i\rangle$-th cycle where error vector $\left\{\Delta F_{\Gamma}\right\}_{\langle i\rangle}\left(=\left\{F_{\Gamma}\right\}_{\langle i\rangle}-\left\{\bar{P}_{\Gamma}\right\}\right)$, tangent stiffness $\left[K_{\Gamma}\right]_{\langle i\rangle}$ and total potential $W_{\langle i\rangle}$ are obtained for $\left\{d_{\Gamma}\right\}_{\langle i\rangle}$. By the Taylor's expansion, the total potential is written for increment $\Delta\left\{d_{\Gamma}\right\}$ as follows :

$$
\begin{aligned}
& W\left(\left\{d_{\Gamma}\right\}_{\langle i\rangle}+\Delta\left\{d_{\Gamma}\right\}\right)=W_{\langle i\rangle}+\left\{\Delta F_{\Gamma}\right\}_{\langle i\rangle}^{T} \Delta\left\{d_{\Gamma}\right\} \\
& +\frac{1}{2} \Delta\left\{d_{\Gamma}\right\}^{T}\left[K_{\Gamma}\right]_{\langle i\rangle} \Delta\left\{d_{\Gamma}\right\}+0\left(\Delta\left\{d_{\Gamma}\right\}^{3}\right)
\end{aligned}
$$

If the whole $\left\{\Delta F_{\Gamma}\right\}_{\langle i\rangle}$ is put on the tangential correction, namely $\Delta\left\{d_{\Gamma}\right\}=-\left[K_{\Gamma}\right]_{\langle i\rangle}^{-1}\left\{\Delta F_{\Gamma}\right\}_{\langle i\rangle}$, we have

$$
\begin{aligned}
\Delta W & =-\frac{1}{2} R_{\langle i\rangle}^{2}+0\left(\left\{\Delta F_{\Gamma}\right\}_{\langle i\rangle}^{3}\right) \\
R_{\langle i\rangle} & =\sqrt{\left\{\Delta F_{\Gamma}\right\}_{\langle i\rangle}^{T}\left[K_{\Gamma}\right]_{\langle i\rangle}^{-1}\left\{\Delta F_{\Gamma}\right\}_{\langle i\rangle}}
\end{aligned}
$$

This $1 / 2 \cdot R_{\langle i\rangle}^{2}$ is representing the first approximation of potential rise at $\left\{d_{\Gamma}\right\}_{\langle i\rangle}$ from the (relative) minimum at $\left\{d_{\Gamma}\right\}^{\mathrm{E}}$. But, unless $\left\{\Delta F_{\Gamma}\right\}_{\langle i\rangle}$ is small enough, that decrease can be overcome by the remaining terms.

Then, by the use of factor $\theta_{\langle i\rangle}\left(0<\theta_{\langle i\rangle} \leq 1\right)$, let a fraction of error $\left\{\Delta F_{\Gamma}\right\}_{\langle i\rangle}$ be submitted to the tangent correction :

$$
\left\{d_{\Gamma}\right\}_{\langle i+1\rangle}=\left\{d_{\Gamma}\right\}_{\langle i\rangle}-\theta_{\langle i\rangle}\left[K_{\Gamma}\right]_{\langle i\rangle}^{-1}\left\{\Delta F_{\Gamma}\right\}_{\langle i\rangle}
$$

Trivially, the resulting $\left\{F_{\Gamma}\right\}_{\langle i+1\rangle}$ is related to $\left\{F_{\Gamma}\right\}_{\langle i\rangle}$ and $\left\{\bar{P}_{\Gamma}\right\}$ in the form

$$
\begin{gathered}
\left\{F_{\Gamma}\right\}_{\langle i+1\rangle}=\left(1-\theta_{\langle i\rangle}\right)\left\{F_{\Gamma}\right\}_{\langle i\rangle}+\theta_{\langle i\rangle}\left\{\bar{P}_{\Gamma}\right\} \\
+\left\{0\left(\theta_{\langle i\rangle}^{2}\right)\right\}
\end{gathered}
$$


And, by the substitution into expression (20), we have the total potential at $\left\{d_{\Gamma}\right\}_{\langle i+1\rangle}$ written as

$$
W_{\langle i+1\rangle}=W_{\langle i\rangle}-\left(\theta-\frac{\theta^{2}}{2}\right)_{\langle i\rangle} R_{\langle i\rangle}^{2}+0\left(\theta_{\langle i\rangle}^{3}\right)
$$

For a small $\theta_{\langle i\rangle}$, as is seen in (23), the shift from $\left\{F_{\Gamma}\right\}_{\langle i\rangle}$ is directed the more straightly to $\left\{\bar{P}_{\Gamma}\right\}$ : that is, sequence $\left\{\left\{F_{\Gamma}\right\}_{\langle 0\rangle},\left\{F_{\Gamma}\right\}_{\langle 1\rangle}, \cdots\right\}$ can be kept close, to any extent, to the line segment from $\left\{F_{\Gamma}\right\}^{\prime}$ to $\left\{\bar{P}_{\Gamma}\right\}$. At the same time, since $\theta-\theta^{2} / 2>0$ for $0<\theta \leq 1$ in (24), inequality $W_{\langle i\rangle}>W_{\langle i+1\rangle}$ is kept for such a small $\theta_{\langle i\rangle}$.

It is not until factor $\theta_{\langle i\rangle}$ 's are actually specified in a sequence that formula (22) is accomplished. The fractional corrections are steady for smaller $\theta_{\langle i\rangle}$, but the rapidity of convergence comes from larger ones. If $\theta_{\langle i\rangle}$ are fixed to one fraction such as $1 / 2$, theoretically, the whole correction is not attained in a finite iteration. Since product $\theta_{\langle i\rangle}\left\{\Delta F_{\Gamma}\right\}_{\langle i\rangle}$ is submitted to the tangent correction, it is rational for factor $\theta_{\langle i\rangle}$ to be taken larger with decrease of error $\left\{\Delta F_{\Gamma}\right\}_{\langle i\rangle}$. We have mentioned quantity $R_{\langle i\rangle}$ in relation to the total potential. That $R_{\langle i\rangle}$ defined by $(21 \mathrm{~b})$ is a norm of vector $\left\{\Delta F_{\Gamma}\right\}_{\langle i\rangle}$ weighted by $\left[K_{\Gamma}\right]_{\langle i\rangle}^{-1}$, and so scalar $\theta_{\langle i\rangle} R_{\langle i\rangle}$ stands for vector $\theta_{\langle i\rangle}\left\{\Delta F_{\Gamma}\right\}_{\langle i\rangle}$. We now generate factor $\theta_{\langle i\rangle}$ such that $\theta_{\langle i\rangle} R_{\langle i\rangle}$ is kept constant, but to the extent $\theta_{\langle i\rangle} \leq 1$ :

$$
\theta_{\langle i\rangle}=\min \left(\frac{\theta_{0} R_{\langle 0\rangle}}{R_{\langle i\rangle}}, 1\right)
$$

in which $\theta_{0}$ is a quantity called "basic correction factor," initially assumed within $0<\theta_{0} \leq 1$.

A descent in the total potential means that $\left\{d_{\Gamma}\right\}_{\langle i+1\rangle}$ is relatively improved from $\left\{d_{\Gamma}\right\}_{\langle i\rangle}$. But, those differences might become numerically invisible on the final cycles in approaching to $\left\{d_{\Gamma}\right\}^{\mathrm{E}}$; for, as is seen in expression (21), $W_{\langle i+1\rangle}{ }^{-}$ $W_{\langle i\rangle}$ is consisting of the quadratic and higher terms of $\left\{\Delta F_{\Gamma}\right\}_{\langle i\rangle}$. On the contrary, the scalar $R_{\langle i\rangle}$ has an increasing accuracy near the solution. As well as the descent in potential, the shifted $\left\{d_{\Gamma}\right\}_{\langle i+1\rangle}$ is required to stay in the same oneto-one domain with $\left\{d_{\Gamma}\right\}_{\langle i\rangle}$ : for an insufficient $\theta_{0},\left\{d_{\Gamma}\right\}_{\langle i+1\rangle}$ can be thrown beyond the stability boundary; or can be dropped into the singular domain, in case of the simple tension members. Thus, after each correction (22), $\left\{d_{\Gamma}\right\}_{\langle i+1\rangle}$ is examined for the following two :

$$
\begin{aligned}
& \text { A) } \operatorname{det}\left[K_{\Gamma}\right]_{\langle i+1\rangle}>0 \\
& \text { B) } W_{\langle i+1\rangle}<W_{\langle i\rangle} \text { for } \theta_{\langle i\rangle}<1 \\
& R_{\langle i+1\rangle}<R_{\langle i\rangle} \text { for } \theta_{\langle i\rangle}=1
\end{aligned}
$$

If $\mathrm{A})$ or $\mathrm{B}$ ) is not true, the last $\left\{d_{\Gamma}\right\}_{\langle i+1\rangle}$ is abandoned. With a renewed correction factor, the iteration is resumed from the previous $\langle i\rangle$-th: for our $\theta_{\langle i\rangle}$ generated by Eq. (25), the basic $\theta_{0}$ is changed into a smaller one such that $\theta_{\langle i\rangle}$ is halved, namely

$$
\theta_{\text {new }}=\frac{\theta_{\langle i\rangle \text { false }}}{2} \cdot \frac{R_{\langle i\rangle}}{R_{\langle 0\rangle}}
$$

Requirement A) is for $\left\{d_{\Gamma}\right\}_{\langle i\rangle}$ 's to be confined to a stable subdomain, in which the convex $W\left(\left\{d_{\Gamma}\right\}\right)$ and the norm $R\left(\left\{d_{\Gamma}\right\}\right)$ are bounded from below. By the other B), sequence $\left\{W_{\langle 0\rangle}, W_{\langle 1\rangle}, \cdots, W_{\langle L\rangle}\right\}$ and $\left\{R_{\langle L+1\rangle}\right.$, $\left.R_{\langle L+2\rangle}, \cdots\right\}$ are kept monotone-decreasing. Hence the sequence is convergent.

The convergence comes mostly from $R_{\langle i\rangle} \rightarrow 0$. But, if the sequence $\left\{d_{\Gamma}\right\}_{\langle i\rangle}$ is kept by the tangent coefficients to cut right across the stability boundary, factor $\theta_{0}$ is halved repeatedly. This $\theta_{0} \rightarrow 0$ leads to a trivial convergence, $\left\{d_{\Gamma}\right\}_{\langle i+1\rangle}{ }^{-}$ $\left\{d_{\Gamma}\right\}_{\langle i\rangle} \rightarrow\{0\}$, but the limit of $\left\{d_{\Gamma}\right\}_{\langle i\rangle}$ is to a boundary point of the stable subdomain, not to $\left\{d_{\Gamma}\right\}^{\mathrm{E}}$.

Strictly speaking, the above A) is not sufficient to keep $\left\{d_{\Gamma}\right\}_{\langle i\rangle}$ 's within one stable subdomain. If two eigenvalues are turned negative in $\left[K_{\Gamma}\right]_{\langle i\rangle} \rightarrow$ $\left[K_{\Gamma}\right]_{\langle i+1\rangle}$, the sign of $\operatorname{det}\left[K_{\Gamma}\right]$ does not change. When the iteration is started with a relatively large $\theta_{0}$, it can happen that another equilibrium than $\left\{d_{\Gamma}\right\}^{\mathrm{E}}$ is attained as the result of $R_{\langle i\rangle} \rightarrow 0$. (This convergence is excluded if the eigenvalues are observed instead.)

Let the line segment from $\left\{F_{\Gamma}\right\}^{\prime}$ to $\left\{\bar{P}_{\Gamma}\right\}$ be expressed by $\left\{F_{\Gamma}(\rho)\right\}=(1-\rho)\left\{F_{\Gamma}\right\}^{\prime}+\rho\left\{\bar{P}_{\Gamma}\right\}$ $(0 \leq \rho \leq 1)$. To this $\left\{F_{\Gamma}(\rho)\right\}$, there exists a corresponding equilibrium curve $\left\{d_{\Gamma}(\rho)\right\}$ continued from $\left\{d_{\Gamma}\right\}^{\prime}$. Provided the entire $\left\{d_{\Gamma}(\rho)\right\}$ is lying in a stable subdomain $\left(\operatorname{det}\left[K_{\Gamma}\left(\left\{d_{\Gamma}(\rho)\right\}\right)\right]>0\right.$ for $0 \leq \rho \leq 1)$, the line $\left\{F_{\Gamma}(\rho)\right\}$ is closely followed by $\left\{\left\{F_{\Gamma}\right\}_{\langle 0\rangle},\left\{F_{\Gamma}\right\}_{\langle 1\rangle}, \cdots\right\}$ with a smaller $\theta_{0}$, and so the solution $\left\{d_{\Gamma}\right\}^{\mathrm{E}}$ is approached by our $\left\{\left\{d_{\Gamma}\right\}_{\langle 0\rangle},\left\{d_{\Gamma}\right\}_{\langle 1\rangle}, \cdots\right\}$.

\section{SETTLEMENT OF EQUILIBRIUM CONFIGURATION}

The following shape finding is preceded by Ref. 8 ), in which the essential scheme is developed for an assembly of the simple tension members.

\section{(1) Tangent coefficients}

Suppose the cable natural lengths are infinitesimally changed on an equilibrium of our suspended structure. In order to derive the structural response, firstly, we assume that the free 
joints are fictitiously fixed at their preceding equilibrium positions. As for an isolated cable spanned between two fixed points, we have obtained the response of tension components to a differential increment of its natural length, Eqs.(11) and (12) of Sec. 2. Those expressions for our cable elements are collected into a matrix form :

$$
\begin{gathered}
\delta\left\{\boldsymbol{T}_{(C)}\right\}_{\text {Fixed }}=\left[\boldsymbol{\psi}_{(C)}\right] \delta\left\{l_{(C)}\right\} \\
{\left[\boldsymbol{\psi}_{(C)}\right]=\left[\begin{array}{lll}
\{\boldsymbol{\psi}\}_{(1)} & & \\
& \ddots & \\
& & \{\boldsymbol{\psi}\}_{(C)}
\end{array}\right]} \\
\delta\left\{l_{(C)}\right\}=\left\{\delta l_{(1)}, \delta l_{(2)}, \cdots, \delta l_{(C)}\right\}
\end{gathered}
$$

in which subscript "Fixed" means a quantity on the temporary joint positions.

By continuity relation (14) and (16), the above $\delta\{\boldsymbol{T}\}_{(c)}$ 's are superposed on the joints :

$$
\delta\left\{F_{\Gamma}\right\}_{\text {Fixed }}=\left[C^{F}\right]\left[S_{F}^{\prime}\right] \delta\left\{\boldsymbol{T}_{(C)}\right\}_{\text {Fixed }}
$$

Those $\delta F_{\gamma}$ 's are reactive forces to the fictitious constraints. The free joints are now released: by the use of the structural tangent stiffness $\left[K_{\Gamma}\left(\left\{d_{\Gamma}\right\}\right)\right]$, the incremental equilibrium equations for the joint displacements are written as

$$
\left[K_{\Gamma}\right] \delta\left\{d_{\Gamma}\right\}+\left[C^{F}\right]\left[S_{F}^{\prime}\right]\left[\boldsymbol{\psi}_{(C)}\right] \delta\left\{l_{(C)}\right\}=\{0\}
$$

Thus we have the structure's own response to $\delta\left\{l_{(C)}\right\}$ :

$$
\begin{aligned}
& \delta\left\{\boldsymbol{X}_{J}\right\}=\left[\Phi_{X J}\left(\left\{l_{(C)}\right\}\right)\right] \delta\left\{l_{(C)}\right\} \\
& {\left[\Phi_{X J}\right]=} \\
& \quad-\left[C^{F}\right]^{T}\left[K_{\Gamma}\right]^{-1}\left[C^{F}\right]\left[S_{F}^{\prime}\right]\left[\boldsymbol{\psi}_{(C)}\right]
\end{aligned}
$$

where $\delta\left\{d_{\Gamma}\right\}$ in Eq.(30) has been rewritten into the freedom of $\left\{\boldsymbol{X}_{J}\right\}$.

In addition to $\delta\{\boldsymbol{T}\}_{(c) \text { Fixed }}$, the tension components of each element $(c)$ have been changed by the joint displacements: at its fore end $(s=l)$

$$
\begin{aligned}
& \left\{\begin{array}{l}
\delta T_{l x} \\
\delta T_{l y}
\end{array}\right\}_{(c)}=-\left(\left(\frac{1}{\left|\boldsymbol{T}_{l}\right|}+\frac{1}{E A}\right)\left[Q\left(\boldsymbol{T}_{l}\right)\right]^{-1}\right. \\
& \left.\cdot\left\{\begin{array}{l}
T_{l x} \\
T_{l y}
\end{array}\right\}+\left\{\begin{array}{c}
0 \\
w
\end{array}\right\}\right) \delta l_{(c)} \\
& +\left[Q\left(\boldsymbol{T}_{l}\right)\right]^{-1}\left(\left\{\begin{array}{l}
\delta x \\
\delta y
\end{array}\right\}_{j}-\left\{\begin{array}{l}
\delta x \\
\delta y
\end{array}\right\}_{i}\right)
\end{aligned}
$$

For $\{\delta x, \delta y\}_{i}$ and $\{\delta x, \delta y\}_{j}$, their $2 \times C$ submatrices are extracted from the coefficient matrix (31 b) with notation $\left[\Phi_{X}\right]_{i}$ and $\left[\Phi_{X}\right]_{j}$, respectively.

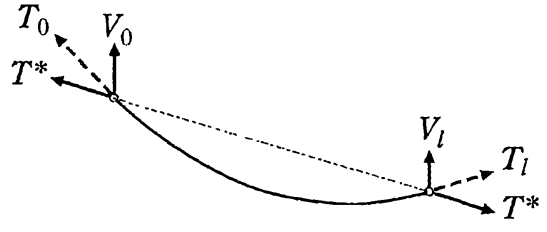

Fig. 4 Chord force

The substitution leads to the variation of tension components written in terms of the independent $\delta\left\{l_{(C)}\right\}$ :

$$
\begin{aligned}
\delta \boldsymbol{T}_{l(c)} & =\boldsymbol{\psi}_{l(c)} \delta l_{(c)} \\
& +[Q]_{(c)}^{-1}\left(\left[\Phi_{X}\right]_{j}-\left[\Phi_{X}\right]_{i}\right) \delta\left\{l_{(C)}\right\}
\end{aligned}
$$

For the later expansion, let this result be given a short notation :

$$
\begin{aligned}
\delta \boldsymbol{T}_{l(c)} & =\left[\Phi_{T]_{(c)}} \delta\left\{l_{(C)}\right\}\right. \\
\text { or } & \\
& =\left[\begin{array}{c}
\left\langle\Phi_{T x}\right\rangle \\
\left\langle\Phi_{T y}\right\rangle
\end{array}\right]_{(c)} \delta\left\{l_{(C)}\right\}
\end{aligned}
$$

In a sagged cable, the chord force given by

$$
T^{*}=T_{l x} \cdot \frac{\sqrt{\bar{x}^{2}+\bar{y}^{2}}}{\bar{x}}
$$

can be employ as a tensile member force (see Fig. 4). Differential $\delta T^{*}$ is written as

$$
\delta T^{*}=\frac{\bar{l}}{\bar{x}} \delta T_{l x}+\frac{T_{l x} \bar{y}}{\bar{l} \bar{x}^{2}}(-\bar{y} \delta \bar{x}+\bar{x} \delta \bar{y})
$$

By substituting the preceding results, we have $\delta T^{*}$ for our element $(c)$ :

$$
\begin{aligned}
& \delta T_{(c)}^{*}=\left(\frac{\bar{l}}{\bar{x}}\left\langle\Phi_{T x}\right\rangle_{(c)}+\frac{T_{l x} \bar{y}}{\bar{l} \bar{x}^{2}}\right. \\
&\left.\cdot\langle-\bar{y}, \bar{x}\rangle\left(\left[\Phi_{X}\right]_{j}-\left[\Phi_{X}\right]_{i}\right)\right) \delta\left\{l_{(C)}\right\}
\end{aligned}
$$

When the magnitude of tension at $s=l$ (or $=$ 0 ) is chosen instead of the chord force, by the differentiation of $T_{l}=\sqrt{T_{l x}^{2}+T_{l y}^{2}}$, we have

$$
\delta T_{l(c)}=\frac{\boldsymbol{T}_{l}^{T}}{T_{l}}\left[\Phi_{T}\right]_{(c)} \delta\left\{l_{(C)}\right\}
$$

\section{(2) Shape-finding scheme}

In our shape finding, the objective values are prescribed to certain equilibrium quantities selected from among

(a) spatial coordinates of joints,

(b) spatial components of cable tensions, and

(c) magnitudes of cable tensions. 
So the preceding $\left\{\boldsymbol{X}_{J}\right\},\left\{\boldsymbol{T}_{l(C)}\right\}$ and $\left\{T_{(C)}^{*}\right\}$ (or $\left.\left\{T_{l(C)}\right\}\right)$ are appointed to the above (a), (b) and (c), where we have formulated their tangent coefficients to change of the cable lengths. The individual subjects taken from those vectors are listed into a set $\boldsymbol{Y}=\left\{Y_{1}, Y_{2}, \cdots, Y_{S}\right\}$, with their required values being denoted by $\boldsymbol{Y}^{*}$. To realize $\boldsymbol{Y}^{*}$ in the structural equilibrium, to the same number $S$, we specify the active cable members which have variable natural lengths. Their lengths are collected into another $\boldsymbol{z}=$ $\left\{z_{1}, z_{2}, \cdots, z_{S}\right\}$. Thus our problem is reduced to solve $\boldsymbol{Y}(\boldsymbol{z})=\boldsymbol{Y}^{*}$ for $\boldsymbol{z}$. In Appendix-B, it is indicated that our shape-finding becomes more practicable if the objective values are set on linear combinations of the above equilirium quantities.

Through the equilibrium computation, Sec. 2 to 4 , the functional relation $\boldsymbol{Y}(\boldsymbol{z})$ is known numerically. By collecting the relevant coefficients from Eqs.(31), (32), (34) and (35), we can have the derivative matrix, $[\partial \boldsymbol{Y}(\boldsymbol{z}) / \partial \boldsymbol{z}]$. The equation $\boldsymbol{Y}(\boldsymbol{z})=\boldsymbol{Y}^{*}$ is now prepared to be iterated upon the tangent coefficients. However, as is well known, the shape-finding problem has its own difficulties: an arbitrary $\boldsymbol{Y}^{*}$ is not necessarily realizable; and, even for a possible $\boldsymbol{Y}^{*}$, we are faced with which members to be taken active. This feasibility problem for a general cable structure seems quite difficult to be clarified. But, once a specific structure is presented to us, we can deduce its possible equilibrium shapes to a certain extent. From this view point, it is here assumed that $\boldsymbol{Y}^{*}$ is lying in a realizable range for our $\boldsymbol{z}$.

The stiffness relations of our cable elements are quite nonlinear: for instance, the longitudinal coefficient in stiffness $\left[\bar{k}\left(\boldsymbol{T}_{l}\right)\right]_{(c)}\left(=\left[Q\left(\boldsymbol{T}_{l}\right)\right]_{(c)}^{-1}\right)$ is comparable to $E A / l$ for $\bar{l} \geq l$, but becomes much smaller for $\bar{l}<l$. That matrix can even be singular as stated in Sec. 2. Thus, similarly to the equilibrium computation, the full correction of error vector $\boldsymbol{Y}-\boldsymbol{Y}^{*}$ on the tangent coefficients can yield an excessive change of $\boldsymbol{z}$. The method of fractional correction is conceptually valid to the present problem also, but, in practice, it is necessary for vector $\boldsymbol{Y}-\boldsymbol{Y}^{*}$ to be transformed into a suitable scalar. The function $\boldsymbol{Y}(\boldsymbol{z})$ does not have its own potential. The absolute value $\left|\boldsymbol{Y}-\boldsymbol{Y}^{*}\right|$ might be considered as an alternative. But, this numeric magnitude is inadequate as a physical quantity; for, first of all, it is a mixture of dimensionally different components, i.e. translational and rotational coordinates of joints, and cable tensions.

We here consider an energy-based conversion of $\boldsymbol{Y}-\boldsymbol{Y}^{*}$. The differences are existing in an equilibrium $\left\{d_{\Gamma}\right\}^{\mathrm{E}}$. With no regard to the equilibrium conditions, first, the free joints listed in $\boldsymbol{Y}$ are thrust to their objective coordinates, and the member forces are shifted accordingly. Next, in those cable elements which are prescribed in $\boldsymbol{Y}^{*}$, the relevant tension components or magnitudes are replaced by the required values. Those disturbed member forces are accumulated into the unbalanced joint forces, say $\left\{\Delta F_{\Gamma}\right\}^{\mathbf{S}}\left(=\left\{F_{\Gamma}\right\}^{\mathbf{S}}-\right.$ $\left.\left\{\bar{P}_{\Gamma}\right\}\right)$. Finally, in the same way to Eq. $(21 \mathrm{~b})$, the magnitude of vector $\left\{\Delta F_{\Gamma}\right\}^{\mathrm{S}}$ is estimated by

$$
R^{\mathrm{S}}=\sqrt{\left\{\Delta F_{\Gamma}\right\}^{\mathrm{S} T}\left[K_{\Gamma}\right]^{\mathrm{E}-1}\left\{\Delta F_{\Gamma}\right\}^{\mathrm{S}}}
$$

in which $\left[K_{\Gamma}\right]^{\mathrm{E}}$ is the tangent stiffness matrix at the preceding equilibrium $\left\{d_{\Gamma}\right\}^{\mathrm{E}}$. Immediately after this estimation of $R^{\mathrm{S}}$, the structure is brought back to $\left\{d_{\Gamma}\right\}^{\mathrm{E}}$.

The fractional correction method is now executed from an initial $\boldsymbol{z}_{0}\left(=\boldsymbol{z}_{\langle 0\rangle}\right)$, with a basic factor $\alpha_{0}$ assumed within $0<\alpha_{0} \leq 1$. Suppose the $\langle j\rangle$-th cycle where $\Delta \boldsymbol{Y}_{\langle j\rangle}\left(=\boldsymbol{Y}_{\langle j\rangle}-\boldsymbol{Y}^{*}\right)$, $[\partial \boldsymbol{Y} / \partial \boldsymbol{z}]_{\langle j\rangle}$ and $R_{\langle j\rangle}^{\mathrm{S}}$ are evaluated on the equilibrium $\left\{d_{\Gamma}\right\}_{\langle j\rangle}^{\mathrm{E}}$ for $\boldsymbol{z}_{\langle j\rangle}$. The formula of fractional correction is written as

$$
\boldsymbol{z}_{\langle j+1\rangle}=\boldsymbol{z}_{\langle j\rangle}-\alpha_{\langle j\rangle}\left[\frac{\partial \boldsymbol{Y}}{\partial \boldsymbol{z}}\right]_{\langle j\rangle}^{-1} \Delta \boldsymbol{Y}_{\langle j\rangle}
$$

where the current $\alpha_{\langle j\rangle}$ is generated by

$$
\alpha_{\langle j\rangle}=\min \left(\frac{\alpha_{0} R_{\langle 0\rangle}^{\mathrm{S}}}{R_{\langle j\rangle}^{\mathrm{S}}}, 1\right)
$$

After the change of cable lengths to $\boldsymbol{z}_{\langle j+1\rangle}$, the responsive equilibrium $\left\{d_{\Gamma}\right\}_{\langle j+1\rangle}^{\mathrm{E}}$ is computed in the displacement method, Sec. 4 .

To the line segment $\boldsymbol{Y}(\xi)=(1-\xi) \boldsymbol{Y}_{0}+\xi \boldsymbol{Y}^{*}$ $(0 \leq \xi \leq 1)$, there is considered a corresponding $\boldsymbol{z}(\xi)$ continued from $\boldsymbol{z}_{0}$, where $\boldsymbol{Y}_{0}=\boldsymbol{Y}\left(\boldsymbol{z}_{0}\right)$. For the convergence to $\boldsymbol{Y}^{*}$, function $\boldsymbol{Y}(\boldsymbol{z})$ is required to be a one-to-one on the entire path, i.e. $\operatorname{det}[\partial \boldsymbol{Y} / \partial \boldsymbol{z}] \neq 0$ for $0 \leq \xi \leq 1$. In the present non-potential problem, the magnitude of vector difference $\boldsymbol{Y}_{\langle j\rangle}-\boldsymbol{Y}^{*}$ is estimated by the scalar $R_{\langle j\rangle}^{\mathrm{S}}$. Thus, the resulting equilibrium after each correction (37) is observed for the following two :

$$
\begin{aligned}
\text { A) } \operatorname{sgn} .(\operatorname{det} & {\left.\left[\frac{\partial \boldsymbol{Y}}{\partial \boldsymbol{z}}\right]_{\langle j+1\rangle}\right) } \\
& =\operatorname{sgn} \cdot\left(\operatorname{det}\left[\frac{\partial \boldsymbol{Y}}{\partial \boldsymbol{z}}\right]_{\langle j\rangle}\right) \\
\text { B) } R_{\langle j+1\rangle}^{\mathrm{S}} & <R_{\langle j\rangle}^{\mathrm{S}}
\end{aligned}
$$

If $\mathrm{A}$ ) or $\mathrm{B}$ ) is not true, the factor $\alpha_{0}$ is regarded still too large. To resume the iteration from the 
previous $\boldsymbol{z}_{\langle j\rangle}$, similarly to Eq.(27), the basic correction factor is changed into

$$
\alpha_{\text {new }}=\frac{\alpha_{\langle j\rangle \text { false }}}{2} \cdot \frac{R_{\langle j\rangle}^{\mathrm{S}}}{R_{\langle 0\rangle}^{\mathrm{S}}}
$$

Differently from the equilibrium problem, it is not always the case that a solution $\boldsymbol{z}^{*}$ exists for a required $\boldsymbol{Y}^{*}$. When iterated for an impossible $\boldsymbol{Y}^{*}$, the derivative matrix $[\partial \boldsymbol{Y} / \partial \boldsymbol{z}]$ comes to be singular with a repeated reduction of $\alpha_{0}$. On such a nearly singular $[\partial \boldsymbol{Y} / \partial \boldsymbol{z}]$, the correction (37) yields a large change of $\boldsymbol{z}$. Even if the equilibrium is obtained for those cable lengths, factor $\alpha_{0}$ will be halved further for violating the requirement $\mathrm{A}$ ) or $\mathrm{B}$ ). After such extreme changes of $\boldsymbol{z}$, it can usually happen that the equilibrium is driven out of the stable domain. Our displacement-method computation is unable to pursue an equilibrium beyond the stability boundary.

Once a cable structure is presented to our shape finding, an unconsciously imposed $\boldsymbol{Y}^{*}$ is not likely to be attainable. But, a preliminary inspection makes it possible to array admissible objectives and active members. So far as $\operatorname{det}[\partial \boldsymbol{Y} / \partial \boldsymbol{z}] \neq 0$ on the aforesaid path $\boldsymbol{z}(\xi)$, our sequence $\left\{\boldsymbol{Y}_{\langle 0\rangle}, \boldsymbol{Y}_{\langle 1\rangle}, \cdots\right\}$ computed with a small enough $\alpha_{0}$ is kept close to $\boldsymbol{Y}(\xi)=$ $(1-\xi) \boldsymbol{Y}_{\mathbf{0}}+\xi \boldsymbol{Y}^{*}$. The difference of $\boldsymbol{z}_{\langle j\rangle}$ from solution $z^{*}$ is represented by the scalar $R_{\langle j\rangle}^{\mathrm{S}}$. So, in addition to the above one-to-one between $\boldsymbol{Y}$ and $\boldsymbol{z}$, function $R^{\mathrm{S}}(\boldsymbol{z})$ is required to be monotonedecreasing on the entire $0 \leq \xi \leq 1$. In its definition, $R^{\mathrm{S}}(\boldsymbol{z})$ seems to embody this monotonicity considerably, unless tangent stiffness $\left[K_{\Gamma}(\boldsymbol{z})\right]^{\mathrm{E}}$ has enormous changes on $\boldsymbol{z}(\xi)$.

\section{NUMERICAL EXAMPLES}

\section{(1) A cantilever supported by deeply hanging cables}

The cantilever shown in Fig. 5 has elastic modulus $20600 \mathrm{kN} / \mathrm{cm}^{2}$, area $63.53 \mathrm{~cm}^{2}$ and moment of inertia $1600 \mathrm{~cm}^{4}$ of cross-section, and weight per unit length $0.5 \mathrm{kN} / \mathrm{m}$. After segmented into five elements of length $10 \mathrm{~m}$, the joints are guyed to another joint fixed at $\{x, y\}=\{30,-15\} \mathrm{m}$ with catenary cables of $E=15700 \mathrm{kN} / \mathrm{cm}^{2}, A=$ $45.24 \mathrm{~cm}^{2}$ and $w=0.364 \mathrm{kN} / \mathrm{m}$. Initially, an equal length $l=30 \mathrm{~m}$ is assumed to all the cable members. Shown in the figure is the equilibrium configuration for those cable lengths with the beam weights being lumped at their joints, which is computed from the joint positions indicated with broken lines. The process of our fractional correction method is shown in Fig. 6,

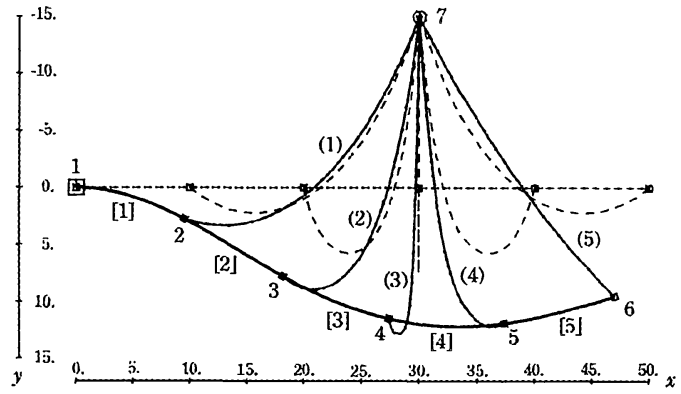

Fig. 5 Initial equilibrium shape of a guyed cantilever
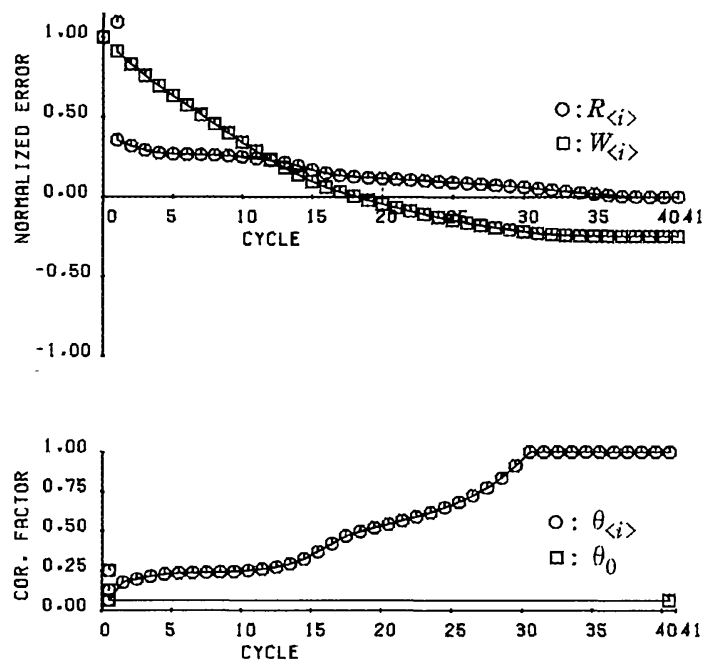

Fig. 6 Convergence to the initial equilibrium

in which "normalized" means that the outermost value in each line is scaled to \pm 1 . Started with $\theta_{0}=0.25$, the basic factor is changed twice to 0.0625 for a long-distant equilibrium state with the deeply hanging cables.

From the above equilibrium state, the cable lengths are computed so that the lumped beam weights are precisely upheld by the cable tensions, i.e. $T_{l y(1) \sim(4)} \rightarrow 5$ and $T_{l y(5)} \rightarrow 2.5 \mathrm{kN}$. The convergence process from basic factor $\alpha_{0}=0.065$ is indicated in Fig. 8, and the equilibrium shape is settled as shown in Fig. 7: the achieved cable lengths are $l_{(1)}=25.2294, l_{(2)}=18.1368$, $l_{(3)}=14.9998, l_{(4)}=18.1366$ and $l_{(5)}=25.4390 \mathrm{~m}$.

\section{(2) A vertically suspended girder}

The girder shown in Fig.9 is divided into eight elements of length $10 \mathrm{~m}$, and which are assumed to have elastic modulus $20600 \mathrm{kN} / \mathrm{cm}^{2}$, area $1200 \mathrm{~cm}^{2}$ and moment of inertia $2667000 \mathrm{~cm}^{4}$ of cross-section, and weight per unit length $9.24 \mathrm{kN} / \mathrm{m} . \quad E=19620 \mathrm{kN} / \mathrm{cm}^{2}, A=22.04 \mathrm{~cm}^{2}$ 


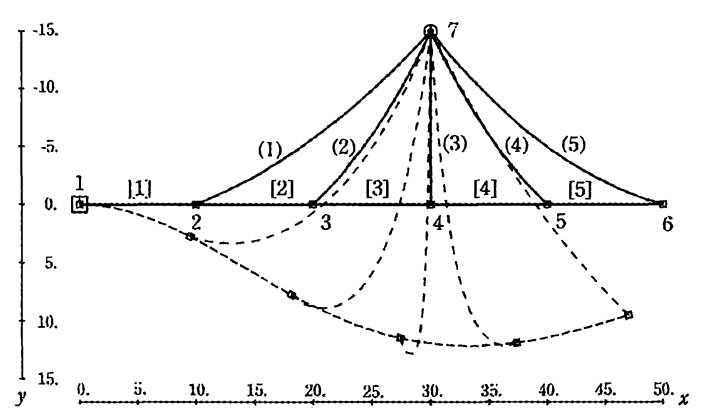

Fig. 7 After settlement of cable lengths

and $w=0.1697 \mathrm{kN} / \mathrm{m}$ are given to the main-cable elements; and $E=15695 \mathrm{kN} / \mathrm{cm}^{2}, A=3.50 \mathrm{~cm}^{2}$ and $w=0.02698 \mathrm{kN} / \mathrm{m}$, to the hanger cables. Cable joint 10 and 18 are fixed at $\{x, y\}=$ $\{0,-20\}$ and $\{80,-20\} \mathrm{m}$, and beam joint 1 and 9 are supported by horizontal rollers at height $y=0$. At the beginning of computation, the joints are located at $x=0,10, \cdots, 80 \mathrm{~m}$ on level $y=0,-20 \mathrm{~m}$, and where the initial cable lengths are assumed by their joint-to-joint distances.

The objective conditions for all the 15 cables: the beam joints are required to be on height $y=0 \mathrm{~m}$, with the cable joints staying at $x=$ $10,20, \cdots, 70 \mathrm{~m}$; and, in the chained (1) to (8), the degree of sag is specified by $y=-4 \mathrm{~m}$ at the center joint 14 .

When computed as the catenary elements, the shape finding was not successful. This result comes from the following: in the initial equilibrium, all the hanger cables are (nearly) in the singular state, that is, are almost in vertical hanging with the joint-to-joint distances less than their member lengths (see Fig. 1). Our displacement method can deal with such a singular state in equilibrium computation. ${ }^{12)}$ But, in the shape finding, the tangent coefficients to variation of their natural lengths become quite different in quality (far small) from the ordinary configurations. The tangent correction by (37) with a usual $\alpha_{\langle j\rangle}$ yields an extreme change of cable lengths such as to negative values.

Next, the same shape finding is executed for the simple tension members. Since the hanger cables come to be slackened toward the initial equilibrium, a vertical roller support is added to joint 5 to stabilize the girder. This equilibrium state is shown by the broken lines in Fig. 9. As stated in Appendix-A, the slackened cable lengths found in a structural equilibrium are immediately replaced by the spatial joint-to-joint lengths, and the tangent approximation (37) is continued for the objective values. In this shape finding for $\alpha_{0}=0.2$, the convergence of $R_{\langle j\rangle}^{\mathrm{S}}$ is obtained as
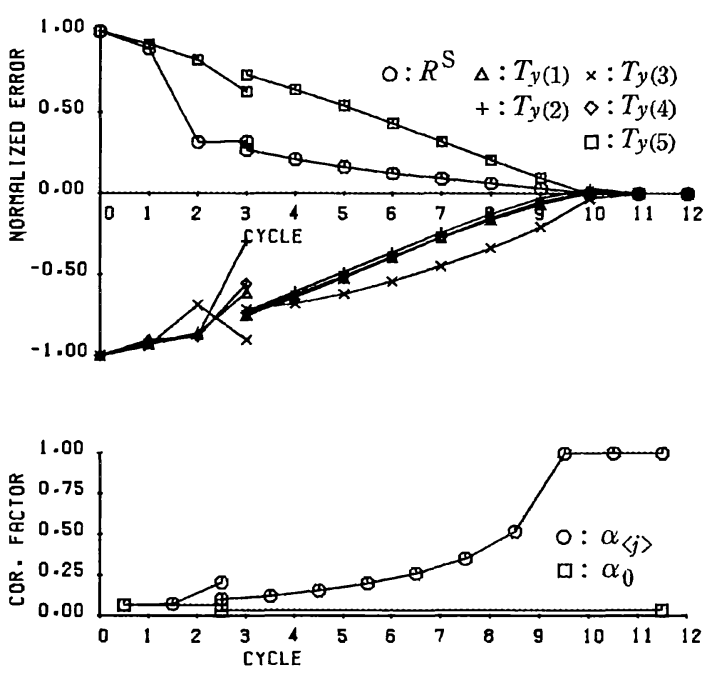

Fig. 8 Convergence of the shape finding

shown in Fig. 10. Shown in Fig. 9 is the resulting equilibrium configuration. The achieved cable lengths and their tensions are listed in Table 1. This result is followed by the shape computation as the elastic catenary elements: after only one full correction $\left(\alpha_{0}=1\right)$, the structure is shifted within the same allowable error $10^{-6}(\mathrm{kN} \cdot \mathrm{m})^{1 / 2}$ for $R^{\mathrm{S}}$. Those quite small changes are invisible in the decimals of Table 1 (chord force $T^{*}$ of a catenary cable corresponds to axial tension $T$ of a straight cable).

\section{(3) A cable-trussed bridge}

The cable-trussed bridge shown in Fig. 11 is made with the use of compressive axial members, namely $(\underline{5}),(\underline{7}),(\underline{12})$ and $(\underline{14})$. The girder has area $0.2784 \mathrm{~m}^{2}$ and moment of inertia $0.1618 \mathrm{~m}^{4}$ of cross-section, elastic modulus $20600 \mathrm{kN} / \mathrm{cm}^{2}$ and weight per unit length $32.15 \mathrm{kN} / \mathrm{m}$, which is divided into $l_{[1]}=l_{[8]}=16, l_{[2]}=l_{[7]}=20, l_{[3]}=$ $l_{[6]}=23$ and $l_{[4]}=l_{[5]}=15 \mathrm{~m}$. Tower member [9] has length $20 \mathrm{~m}$, elastic modulus $20600 \mathrm{kN} / \mathrm{cm}^{2}$, area $0.0672 \mathrm{~m}^{2}$, moment of inertia $0.006656 \mathrm{~m}^{4}$ and weight per unit length $5.17 \mathrm{kN} / \mathrm{m}$, which is rigidly connected to the girder at joint 5 instead of to the ground. $E=15700 \mathrm{kN} / \mathrm{cm}^{2}, A=57.9 \mathrm{~cm}^{2}$ and $w=0.466 \mathrm{kN} / \mathrm{m}$ are assumed to cable member (1), (4), (8) and (11); and $E=15700$, $A=32.57$ and $w=0.262$, to the remaining cable members. Those cable members are treated as the elastic catenary. $\bar{E}=20600, \bar{A}=288$ and $\bar{w}=2.218$ are for axial member $(\underline{5})$ and $(\underline{12})$; and $\bar{E}=20600, \bar{A}=160$ and $\bar{w}=1.232$ for $(\underline{7})$ and $(\underline{14})$. Joint 5 is hinged to the ground at the origin of $\{x, y\}$-coordinates, and joint 1 and 9 are 


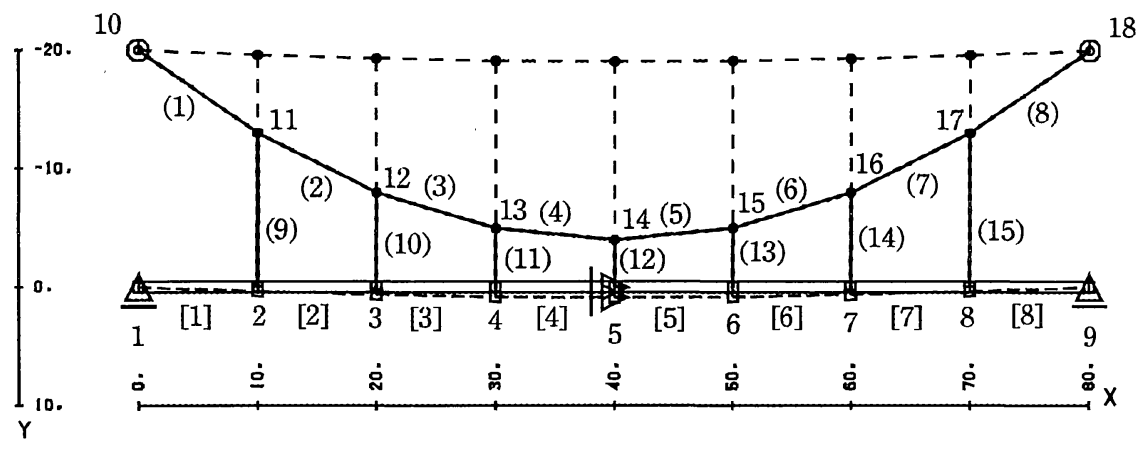

Fig. 9 Initial and settled equilirium shapes of a suspended girder
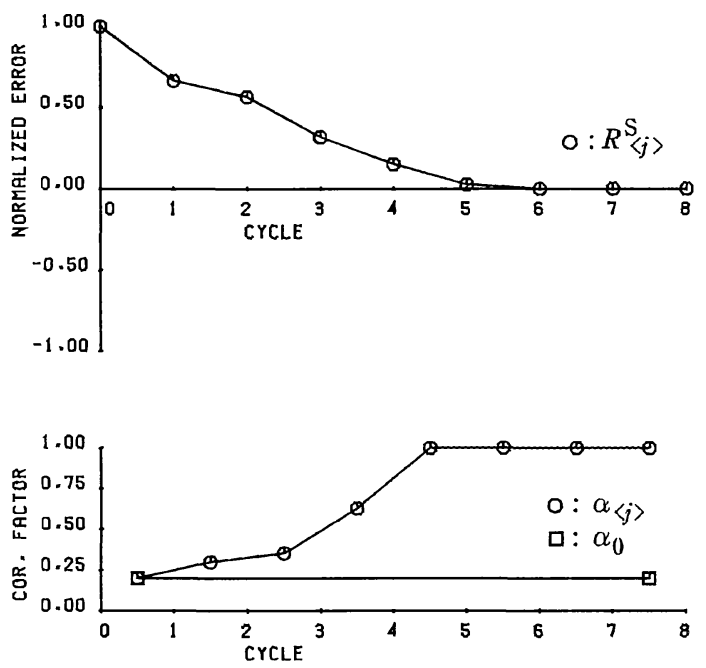

Fig. 10 Iteration process for the simple tension members

kept on $y=0$ by horizontal rollers.

Initially, joint 2 to 8 are placed on $y=0$ with no elongations in the beam elements; and joint $12,11,10,13$ and 14 are just above joint 3, 4, 5,6 and 7 on height $y=-20$, respectively. The spatial distances between those joint positions are assumed to the cable and axial members as their initial lengths. Released from those joint positions, the equilibrium configuration is obtained as indicated by broken lines in Fig. 11, where the deflections at the beam joints are $y_{2}=y_{8}=7.64$, $y_{3}=y_{7}=9.75$ and $y_{4}=y_{6}=3.18 \mathrm{~cm}$.

The followings are required for the 14 variable member lengths: the beam joints are kept exactly on $y=0$; the cable joints are positioned at height $y_{11}=y_{13}=-16$ and $y_{12}=y_{14}=-10 \mathrm{~m}$; and the compressive axial members are inclined with diagonal proportion $1: \pm 2$. Those requirements are listed specifically in Table 2. The convergence process for $\alpha_{0}=0.1$ is shown in
Table 1 Result of shape finding

\begin{tabular}{lr|r|r}
\multicolumn{2}{c|}{ cable } & $l \quad(\mathrm{~m})$ & $T(\mathrm{kN})$ \\
\hline$(1)$ & $(8)$ & 12.1940 & 576.07 \\
$(2)$ & $(7)$ & 11.1661 & 527.45 \\
$(3)$ & $(6)$ & 10.4275 & 492.52 \\
$(4)$ & $(5)$ & 10.0387 & 474.14 \\
$(9)$ & $(15)$ & 12.9717 & 92.58 \\
$(10)$ & $(14)$ & 7.9816 & 92.51 \\
$(11)$ & $(13)$ & 4.9900 & 92.47 \\
$(12)$ & 3.9933 & 92.45
\end{tabular}

Fig. 12. In the settled equilibrium shape (see Fig. 11), the disagreements of the respective $Y_{s}$ from $Y_{s}^{*}$ are less than $10^{-14} \mathrm{~m}$, and the beam bendings are correspondingly negligible for their self-weights lumped at the joints. The attained member lengths, and the chord and axial forces are given in Table 3.

\section{CONCLUDING REMARKS}

The "elastic catenary" was formulated more than a hundred years ago, but which had been held from practical utilization until the computational age. The force-method treatment for the compatibility can be extended directly to an assembly of those catenary members. ${ }^{7)}$ But, the displacement method is employed for our structure compounded of cable and beam members, in which the fractional correction method is applied to the layered numerical problems, namely, for the compatible tension components in each catenary cable and for the structural equilibrium. Those equilibrium computations are based on analytical treatment of the nonlinearity exhibited by the consisting members: the convergence to solution is secured for a convex potential problem, so except for the structural instability.

The present shape finding for a beam-cable 


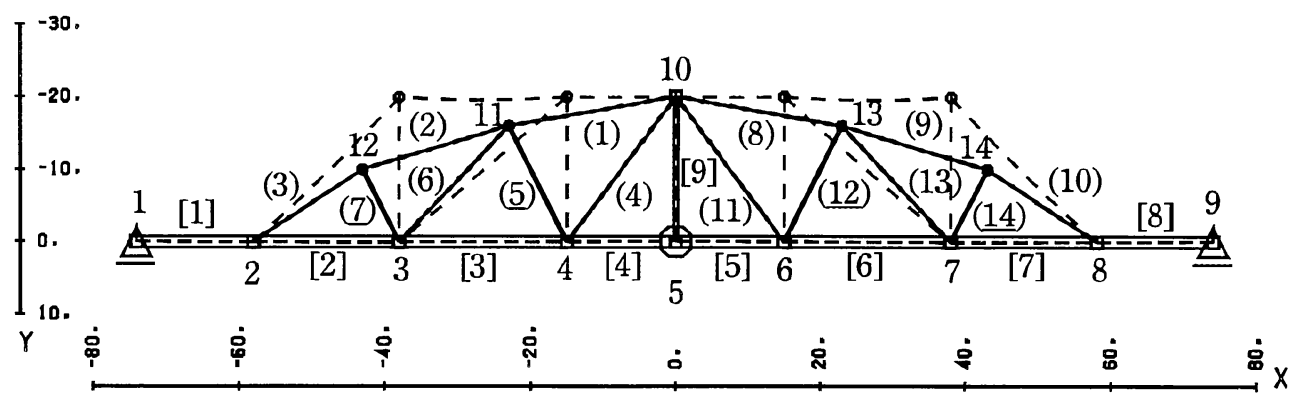

Fig. 11 Initial and settled equilirium shapes of a cable-trussed bridge

Table 2 Requirements in the shape finding

\begin{tabular}{l|c}
\multicolumn{1}{c|}{$Y_{s}$} & $Y_{s}^{*}(\mathrm{~m})$ \\
\hline$Y_{1}=y_{2}$ & 0. \\
$Y_{2}=y_{3}$ & 0. \\
$Y_{3}=y_{4}$ & 0. \\
$Y_{4}=y_{6}$ & 0. \\
$Y_{5}=y_{7}$ & 0. \\
$Y_{6}=y_{8}$ & 0. \\
$Y_{7}=y_{11}$ & -16. \\
$Y_{8}=y_{12}$ & -10. \\
$Y_{9}=y_{13}$ & -16. \\
$Y_{10}=y_{14}$ & -10. \\
$Y_{11}=x_{11}-x_{4}-0.5 y_{11}+0.5 y_{4}$ & 0. \\
$Y_{12}=x_{12}-x_{3}-0.5 y_{12}+0.5 y_{3}$ & 0. \\
$Y_{13}=x_{13}-x_{6}+0.5 y_{13}-0.5 y_{6}$ & 0. \\
$Y_{14}=x_{14}-x_{7}+0.5 y_{14}-0.5 y_{7}$ & 0.
\end{tabular}

structure is developed from the preceding one for a mere assembly of straight cables. ${ }^{8}$ ) In that extension, no fundamental difficulties are encountered beyond the structural complexity. This is indicating a potential capability of the displacement-method system. The objective state is approached also by the fractional technique. Even in a non-potential problem, if an adequate scalar is available for the deviation, that iteration can be applied for the solution existing in a one-to-one correspondence. The present shape finding is a problem of simultaneous algebraic equations with quite nonlinear behaviors of each catenary element. In that iteration scheme, there might be considered other additional tactics for a more persistent achievement over their tightened and slackened states. On the other hand, the shape determination for the straight tension members yields a steady convergence owing to the simple treatment of their relaxation (AppendixA), and from which the computation could be continued as the catenary cables, if necessary.
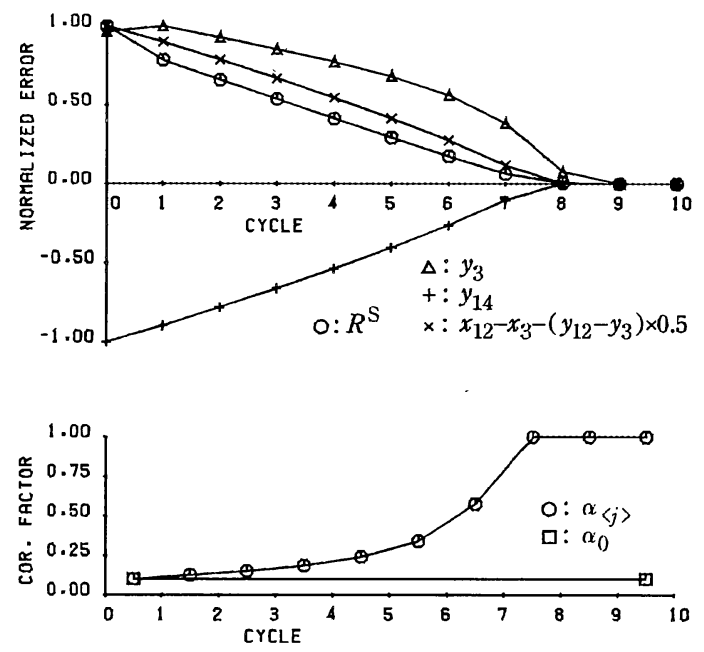

Fig. 12 Iteration process of the shape finding

Table 3 Settled member lengths and chord/axial forces Cable and Compressive Members (in kN, m)

\begin{tabular}{c|c|c}
\hline \multicolumn{1}{|c|}{$c)$} & length & chord/axial force \\
\hline$(1)(8)$ & 23.2810 & 2433.3 \\
$(2)(9)$ & 20.8367 & 1060.4 \\
$(3)(10)$ & 17.9907 & 1047.5 \\
$(4)(11)$ & 24.9418 & 1931.4 \\
$(\underline{5})(\underline{12})$ & 17.8916 & -1015.8 \\
$(6)(13)$ & 21.8732 & 1356.0 \\
$(\underline{7})(\underline{14})$ & 11.1814 & -322.3 \\
\hline
\end{tabular}

Beam Members ( in kN)

\begin{tabular}{l|r|c|c}
\hline$[e]$ & axial force & {$[e]$} & axial force \\
\hline$[1][8]$ & 0.0 & {$[2][7]$} & -871.6 \\
{$[3][6]$} & -1943.1 & {$[4][5]$} & -3556.4 \\
{$[9]$} & -3996.9 & & \\
\hline
\end{tabular}




\section{APPENDIX A. \\ SIMPLE TENSION MEMBER AND COMPRESSIVE AXIAL MEMBER}

In cable element $(c)$, let the distributed selfweight be lumped into halves $w l / 2$ at its both ends. When spanned to $\{\bar{x}, \bar{y}\}$, this straight cable is lengthened by

$$
\Delta \bar{l}(=\bar{l}-l)=\sqrt{\bar{x}^{2}+\bar{y}^{2}}-l
$$

With its no resistance to compression, the tension vector $\overline{\boldsymbol{T}}$ is written as follows :

$$
\begin{aligned}
& \left\{\begin{array}{l}
\bar{T}_{x} \\
\bar{T}_{y}
\end{array}\right\}=\frac{T}{\bar{l}}\left\{\begin{array}{l}
\bar{x} \\
\bar{y}
\end{array}\right\} \\
& T=\left\{\begin{array}{cc}
\frac{E A}{l} \Delta \bar{l} & \text { for } \Delta \bar{l} \geq 0 \\
0 & \text { for } \Delta \bar{l}<0
\end{array}\right.
\end{aligned}
$$

Consider joint $i$ and $j$ to which element $(c)$ is attached: $\overline{\boldsymbol{x}}=\boldsymbol{x}_{j}-\boldsymbol{x}_{i}$ and $\{\boldsymbol{x}\}_{(c)}=\left\{\boldsymbol{x}_{i}, \boldsymbol{x}_{j}\right\}$. As shown in Fig. 13, the joint forces, $\{\boldsymbol{T}\}_{(c)}=$ $\left\{\boldsymbol{T}_{i}, \boldsymbol{T}_{j}\right\}$, are here defined after inclusion of the lumped self-weights :

$$
\begin{aligned}
& \left\{\begin{array}{l}
T_{x} \\
T_{y}
\end{array}\right\}_{i}=-\frac{T}{\bar{l}}\left\{\begin{array}{l}
\bar{x} \\
\bar{y}
\end{array}\right\}-\left\{\begin{array}{c}
0 \\
w l / 2
\end{array}\right\} \\
& \left\{\begin{array}{l}
T_{x} \\
T_{y}
\end{array}\right\}_{j}=\frac{T}{\bar{l}}\left\{\begin{array}{l}
\bar{x} \\
\bar{y}
\end{array}\right\}-\left\{\begin{array}{c}
0 \\
w l / 2
\end{array}\right\}
\end{aligned}
$$

Accordingly, the element potential is given by the sum of the strain energy and the self-weight potential :

$$
U_{(c)}+V_{(c)}=\frac{T^{2} l}{2 E A}-\frac{w l}{2}\left(y_{j}+y_{i}\right)
$$

By differentiating the above relations with respect to $\overline{\boldsymbol{x}}$, we have the tangent stiffness matrix :

$$
\begin{gathered}
\delta \overline{\boldsymbol{T}}=[\bar{k}(\overline{\boldsymbol{x}})]_{(c)} \delta \overline{\boldsymbol{x}} \\
{[\bar{k}]_{(c)}=\left[\bar{k}_{M}(\overline{\boldsymbol{x}})\right]_{(c)}+\left[\bar{k}_{G}(\overline{\boldsymbol{x}})\right]_{(c)}} \\
{\left[\bar{k}_{M}\right]_{(c)}=\frac{E A}{l \bar{l}^{2}}\left[\begin{array}{rr}
\bar{x} \bar{x} & \bar{x} \bar{y} \\
\bar{x} \bar{y} & \bar{y} \bar{y}
\end{array}\right]} \\
{\left[\bar{k}_{G}\right]_{(c)}=\frac{T}{\bar{l}^{3}}\left[\begin{array}{rr}
\bar{y} \bar{y} & -\bar{x} \bar{y} \\
-\bar{x} \bar{y} & \bar{x} \bar{x}
\end{array}\right]}
\end{gathered}
$$

If $\Delta \bar{l}<0$, zero matrix stands for both $\left[\bar{k}_{M}\right]$ and $\left[\bar{k}_{G}\right]$. Through $\delta \overline{\boldsymbol{x}}=\delta \boldsymbol{x}_{j}-\delta \boldsymbol{x}_{i}$ and $\delta \overline{\boldsymbol{T}}=\delta \boldsymbol{T}_{j}=$ $-\delta \boldsymbol{T}_{i}$, those $[\bar{k}],\left[\bar{k}_{M}\right]$ and $\left[\bar{k}_{G}\right]$ are rewritten into the $4 \times 4$ matrices, $[k]_{(c)},\left[k_{M}\right]_{(c)}$ and $\left[k_{G}\right]_{(c)}$, respectively.

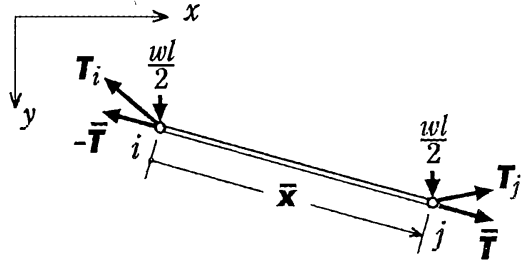

Fig. 13 Straight cable

With substitution of ( $42 \mathrm{~b})$, the quadratic form of matrix $[\bar{k}]_{(c)}$ can be developed into

$$
\begin{aligned}
& \delta^{2} I_{(c)}\left(=\delta \overline{\boldsymbol{x}}^{T}[\bar{k}]_{(c)} \delta \overline{\boldsymbol{x}}\right) \\
& =\left\{\begin{array}{cc}
\frac{E A}{\bar{l}^{3}}(\bar{x} \delta \bar{x}+\bar{y} \delta \bar{y})^{2} \\
+\frac{T}{\bar{l}}\left(\delta \bar{x}^{2}+\delta \bar{y}^{2}\right) & \text { for } \Delta \bar{l} \geq 0 \\
0 & \text { for } \Delta \bar{l}<0
\end{array}\right.
\end{aligned}
$$

So far as tensioned $(\Delta \bar{l}>0)$, matrix $[\bar{k}]_{(c)}$ is positive definite; and becomes singular into the circumferential direction at limit $\sqrt{\bar{x}^{2}+\bar{y}^{2}} \rightarrow l$. In the circular domain of $\Delta \bar{l}<0$, this tension element is singular into any directions.

Similarly to Eqs.(11) and (12) for a catenary element, we now consider the tangent coefficients to variation $\delta l$ of natural length with $\overline{\boldsymbol{x}}$ being fixed. From Eq.(42b), $\delta T=-E A \bar{l} / l^{2} \cdot \delta l$ for $\Delta \bar{l} \geq 0$. We have the differentiation of Eqs.(43) written as

$$
\begin{gathered}
\delta\{\boldsymbol{T}\}_{(c)}=\{\boldsymbol{\psi}\}_{(c)} \delta l=\left\{\begin{array}{c}
\boldsymbol{\psi}_{i} \\
\boldsymbol{\psi}_{j}
\end{array}\right\} \delta l_{(c)} \\
\boldsymbol{\psi}_{i}=\frac{E A}{l^{2}}\left\{\begin{array}{c}
\bar{x} \\
\bar{y}
\end{array}\right\}-\left\{\begin{array}{c}
0 \\
w / 2
\end{array}\right\} \\
\boldsymbol{\psi}_{j}=-\frac{E A}{l^{2}}\left\{\begin{array}{l}
\bar{x} \\
\bar{y}
\end{array}\right\}-\left\{\begin{array}{c}
0 \\
w / 2
\end{array}\right\}
\end{gathered}
$$

When the simple tension elements are active in the shape finding, it can happen that some of them are slackened $(\Delta \bar{l}<0)$ in the passing structural equilibria. Their tangent coefficients have no validity any more. As a counter treatment, we have their natural lengths replaced by the spatial joint-to-joint lengths $(\Delta \bar{l}=0)$, prior to the simultaneous approximation of all the cable lengths upon $[\partial \boldsymbol{Y}(\boldsymbol{z}) / \partial \boldsymbol{z}]$, Eq.(37).

When the incompressibility for $\Delta \bar{l}<0$ is eliminated, we have the correspondent relations for the usual axial-force element. For simplicity, let the same notations such as $\{\boldsymbol{T}\}_{(c)}$ be employed even for those compressible members. In the domain of $\Delta \bar{l}<0$, this element is not singular, but unstable: in Eq.(46), $\delta^{2} I_{(c)}<0$ for $\delta \overline{\boldsymbol{x}}$ such that $\overline{\boldsymbol{x}}^{T} \delta \overline{\boldsymbol{x}}=0$. 


\section{APPENDIX B. FOR PRACTICAL SHAPE FINDING}

In Sec. 5, the components selected among vector $\left\{\boldsymbol{X}_{J}\right\},\left\{\boldsymbol{T}_{l(C)}\right\},\left\{T_{(C)}^{*}\right\}$ and $\left\{T_{l(C)}\right\}$ are individually subjected to their objective values. But, those conditions are not sufficient for an actual structure: for instance, some cable tensions connected to a joint might be required to offset their horizontal or vertical components to each other; and some free joints are, to be located on the same height. With no difficulty, the capability of our shape finding is much widened by imposing the objective values on linear combinations of those equilibrium quantities :

$$
\begin{aligned}
Y_{1} & =C_{11} Y_{11}^{\prime}+C_{12} Y_{12}^{\prime}+\cdots+C_{1 K_{1}} Y_{1 K_{1}}^{\prime} \\
& \vdots \\
Y_{s} & \stackrel{\vdots}{=} C_{s 1} Y_{s 1}^{\prime}+\cdots+C_{s K_{s}} Y_{s K_{s}}^{\prime} \\
& \vdots \\
Y_{S} & =C_{S 1} Y_{S 1}^{\prime}+\cdots+C_{S K_{S}} Y_{S K_{S}}^{\prime}
\end{aligned}
$$

where $Y_{s k}^{\prime}$ 's are the direct components taken from the above $\left\{\boldsymbol{X}_{J}\right\}$ to $\left\{T_{l(C)}\right\}$; and $C_{s k}$ 's are relativity constants. The tangent coefficients between $\boldsymbol{Y}$ and $\boldsymbol{z}$ are obtained in the same way: $[\partial \boldsymbol{Y} / \partial \boldsymbol{z}]=[C]\left[\partial \boldsymbol{Y}^{\prime} / \partial \boldsymbol{z}\right]$. In the iterative computation, the first $Y_{s 1}^{\prime}$ is treated a little differently from others in each $Y_{s}$ : when error vector $\Delta \boldsymbol{Y}_{\langle j\rangle}=\boldsymbol{Y}_{\langle j\rangle}-\boldsymbol{Y}^{*}$ is found on the $\langle j\rangle$-th cycle, scalar $R_{\langle j\rangle}^{\mathrm{S}}$ by Eq.(36) is calculated for those unbalanced joint forces which result from the shift of only $Y_{s 1\langle j\rangle}^{\prime}$ 's :

$$
Y_{s 1\langle j\rangle}^{\prime} \rightarrow Y_{s 1\langle j\rangle}^{\prime}-\frac{\Delta Y_{s\langle j\rangle}}{C_{s 1}}, s=1, \cdots, S
$$

In our fractional iteration upon the tangent coefficients, the member lengths in $\boldsymbol{z}$ are improved along by the linear path $\boldsymbol{Y}(\xi)=(1-$ $\xi) \boldsymbol{Y}_{0}+\xi \boldsymbol{Y}^{*}$. Even if the initial $\boldsymbol{Y}_{\mathbf{0}}$ has a long distance to $\boldsymbol{Y}^{*}$, we expect the objective state to be attained in so far as $\operatorname{det}\left[K_{\Gamma}(\xi)\right]^{\mathrm{E}}>0$ and $\operatorname{det}[\partial \boldsymbol{Y} / \partial \boldsymbol{z}] \neq 0$ on the exact path $\boldsymbol{z}(\xi)$ $(0 \leq \xi \leq 1)$. However, in principle, our structural analysis has a difficulty in handling finite strain states: when subjected to finite deformations, the beam elements can easily become unstable. The discretized beam elements themselves are prepared not so much for finite strain states as for finite displacements: the stiffness relations by the separation method ${ }^{15)}$ can deal with any large displacements (as a rigid body), but are still a disputable approximation for finite deformations. So the equilibrium states corresponding to the exact $\boldsymbol{z}(\xi)$ are required to stay in a range of relatively small strains. In our actual computation, those small-strain states are kept by the fractional corrections with a sufficiently small $\alpha_{0}$. But, to convert error vector $\Delta \boldsymbol{Y}_{\langle j\rangle}$ into the scalar $R_{\langle j\rangle}^{\mathrm{S}}$, once in each cycle $\langle j\rangle$, the structure can be deformed extremely by the aforesaid shift of $Y_{s 1\langle j\rangle}^{\prime}$. By the use of a factor such as the previous $\alpha_{\langle j-1\rangle}$ taken in $\boldsymbol{z}_{\langle j-1\rangle} \rightarrow \boldsymbol{z}_{\langle j\rangle}$, we can have $R_{\langle j\rangle}^{\mathrm{S}}$ also for a small disturbance: $Y_{s 1\langle j\rangle}^{\prime}$ 's are shifted for a fractional $\alpha_{\langle j-1\rangle} \Delta \boldsymbol{Y}_{\langle j\rangle}$ instead of by (49), that is

$$
Y_{s 1\langle j\rangle}^{\prime} \rightarrow Y_{s 1\langle j\rangle}^{\prime}-\alpha_{\langle j-1\rangle} \frac{\Delta Y_{s\langle j\rangle}}{C_{s 1}}
$$

and, from the resulting $\left\{\Delta F_{\Gamma}\right\}_{\langle j\rangle}^{\mathrm{S}}$, error $R_{\langle j\rangle}^{\mathrm{S}}$ for the total $\Delta \boldsymbol{Y}_{\langle j\rangle}$ is estimated by

$$
R_{\langle j\rangle}^{\mathrm{S}}=\frac{1}{\alpha_{\langle j-1\rangle}} \sqrt{\left\{\Delta F_{\Gamma}\right\}^{\mathrm{S} T}\left[K_{\Gamma}\right]^{\mathrm{E}-1}\left\{\Delta F_{\Gamma}\right\}^{\mathrm{S}}}\langle j\rangle
$$

\section{REFERENCES}

1) Avent, R.R.: Nonlinear field analysis of structural nets, J. Struct. Div., ASCE, Vol.95, No.ST5, pp.889907, May, 1969.

2) Namita, Y. and Nakanishi, H.: A method of computation for determining the shape of cable structures, Trans. Japan Architectural Inst., No.212, pp.37-45, Oct., 1973 (in Japanese).

3) Ohyama, H. and Kawamata, S.: A problem of surface design for prestressed cable nets, Proc. IASS Pacific Symposium-Part II, Tokyo and Kyoto, pp.103-115, 1972.

4) Schek, H.J.: The force density method for form finding and computation of general networks, Computer Methods in Applied Mechanics and Engineering, Vol.3, pp.115-134, 1974.

5) Argyris, J.H., Angelopoulos, T. and Bichat, B.: A general method for the shape finding of lightweight tension structures, Computer Methods in Applied Mechanics and Engineering, Vol.3, pp.135-149, 1974.

6) Nakanishi, H. and Namita, Y.: Shape determination analysis of cable structures by means of the methods for optimization problem, Trans. Japan Architectural Inst., No.238, pp.13-23, Dec., 1975 (in Japanese).

7) Ai, M., Nishioka, T. and Okumura, T.: A theoretical analysis of cable assemblies, Proc. JSCE, No.260, pp.17-32, Apr., 1977 (in Japanese).

8) Ai, M. and Nishino, F.: An equilibrium and a shapedetermination analysis of cable assemblies upon the displacement method, Proc. of Symposium on Computational Methods in Structural Engineering, Vol.12, JSSC, pp.109-114, Jul., 1988 (in Japanese).

9) Nishino, F., Duggal, R. and Loganathan, S.: Design analysis of cable networks, J. Struct. Engng., ASCE, Vol.115, No.12, pp.3123-3141, Dec., 1989.

10) Maeda, Y., Hayashi, M. and Maeda, K.: Analytical calculation of sagging cable, Proc. JSCE, No.257, Jan., 1977 (in Japanese).

11) Goto, S.: Tangent stiffness equation of flexible cable and some considerations, Proc. JSCE, No.270, pp.4149, Feb., 1978 (in Japanese). 
12) Ai, M. and Ohsumi, Y.: The elastic catenary as a displacement-method element, Structural Eng./ Earthquake Eng., JSCE, Vol.17, No.2, pp.241s-246s, Oct., 2000.

13) Rough, E.J.: A Treatise on Analytical Statics, Cambridge Univ. Press, Cambridge, England. Vol.1, 2nd Edition, 1896.
14) Ai, M., Nakano, T. and Masuda, S.: A consideration on the slackened and tightened cables, Structural Eng./Earthquake Eng., JSCE, Vol.11, No.3, pp.141s144s, Oct., 1994.

15) Ai, M. and Nishino, F.: Mechanics in geometrically nonlinear problem of discrete system and application to plane frame-works, Proceedings of JSCE, No.304, pp.17-32, Dec., 1980 (in Japanese).

(Received March 19, 2003)

\section{ケーブル構造の変位法つり合い系における形状決定解析}

\section{阿井 正博・今井 裕敬}

一般に，ケーブル構造の形状とは自重やケーブル張力が作用したつり合いの状態であり，幾何学的 非線形性のために, 所定の形状/内力状態を実現するには部材長などを調整するいわゆる形状決定解 析を必要とする. また，ケーブルは柱や曲げ部材と組合わせて用いられるのが多くの吊構造であり， つり合い解析としては, 汎用性の上から有限変位変位法が考えられる. 変位法では, 直線ケーブル要 素が実用的であるが, たわみが無視できない大規模構造などでは要素分割を要する. 本文では, 自重 と伸びの効果が厳密に表現される弾性カテナリー要素を採用しており, 両端節点位置の適合条件に対 する各要素張力を別途に応力法計算しながら, 構造の変位法つり合い計算を行っている. その上で, ケーブル長の微小増分に対する諸量応答の接線係数を誘導してつり合い解析と組合わせることによっ て, はりーケーブル構造系に対する 1 つの形状決定法を提案している. つり合い形状の実現可能領域 を一般構造として論ずることは行っていないが, 可変ケーブルと被決定量とを同数設定して行う確定 論的方法である. 